\title{
Comparative study of larval head structures of Megaloptera (Hexapoda)
}

\author{
RoLF G. BEUTEL and Frank FRIEDRICH
}

Institut für Spezielle Zoologie und Evolutionsbiologie, FSU Jena, 07743 Jena, Germany; e-mail: Rolf.Beutel@uni-jena.de

Key words. Megaloptera, larvae, head, anatomy, phylogeny

\begin{abstract}
External and internal head structures of the larva of Neohermes are described in detail. The results are compared to conditions found in other representatives of Corydalidae, in Sialidae, and in Raphidioptera and Neuroptera. Corydalidae and Sialidae are mainly characterised by plesiomorphic features such as distinct frontal and coronal sutures, six stemmata, a movable labrum with a full set of muscles, a thin tentoriomandibular muscle, a distinct maxillary groove, 4-segmented maxillary palps, an oblique arrangement of the extrinsic maxillary muscles, a labium with all components except for the glossae and paraglossae, 3-segmented labial palps, and a largely complete muscle system. The partly reduced maxillary groove, the strongly elongated stipes, the apical membranous stipital collar, the close connection of the palp and galea, the subdivision of the galea, the strongly shortened palp, the bipartite tentoriocardinal and tentoriostipital muscles, the anterolateral submental notch, the lateral tentoriopharyngeal muscle, and the postgular plate are autapomorphies of Corydalidae. An additional antennomere is present in large corydalid species. The monophyly of the subfamilies Corydalinae and Chauliodinae is not supported by features of the larval head. The reduced condition of the anterior and dorsal tentorial arms and the antennal muscles, the transverse labial muscle, the loss of muscles of the salivary duct, and possibly the lateral origin of M. frontopharyngalis posterior are autapomorphies of Sialidae. The monophyly of Megaloptera is suggested by the insertion of a peg-like or spine-shaped sensillum on the antepenultimate antennomere, the vestigial salivary duct, and a verticopharyngeal muscle composed of several bundles. The distinct neck region, the parietal ridge, and the anterior position of the posterior tentorial grooves are features shared by Corydalidae and Raphidioptera. Arguments in favour of a clade comprising Megaloptera and Raphidioptera are the presence of a circular ridge anterad of the neck region, an increased number of Semper cells and retinula cells in the stemmata, the presence of a gula in adults, a similar cleaning behaviour, and molecular data. Potential autapomorphies of Neuropterida are the prognathism of the larvae and the absence of a mandibular mola. However, the polarity of these characters is unclear. A derived condition found in most groups of Endopterygota, but not in Hymenoptera, is the presence of one or two sensorial appendages on one of the intermediate antennomeres, usually the penultimate. Larval autapomorphies of Endopterygota suggested in earlier studies are confirmed for Corydalidae.
\end{abstract}

\section{INTRODUCTION}

Megaloptera is one of three neuropterid orders and arguably one of the most plesiomorphic lineages of Endopterygota (Theischinger, 1991; New \& Theischinger, 1993). The monophyly of the order was often challenged (e.g., Achtelig, 1967; Büning, 1998) but was supported in recent studies based on molecular (Haring \& Aspöck, 2004) and new morphological data (Aspöck \& Aspöck, 2008).

The short-lived adults are medium sized (Sialidae) to very large (Corydalidae). The larvae are predacious, exclusively aquatic and equipped with lateral abdominal gills (Neunzig \& Baker, 1991). The order is subdivided into the distinctive families Sialidae (seven genera, ca. 70 spp.) and Corydalidae (ca. 25 genera, ca. 200 spp.), the latter comprising the subfamilies Corydalinae and Chauliodinae (Glorioso, 1981; Aspöck \& Aspöck, 2005). Sialidae occur on all continents with the exception of Antarctica, but are restricted to the east coast of Australia and to the southernmost and north eastern part of Africa. Chauliodinae occur in North America, Chile, Australia, New Zealand, Madagascar, southern Africa and Asia, and Corydalinae in the New World, southern Africa and Southeast Asia (Glorioso, 1981; Grimaldi \& Engel, 2005). Adults of Corydalinae reach a wing span up to 175 mm (Grimaldi \& Engel, 2005). Males of Corydalus are characterised by extremely elongate mandibles. The larvae of Corydalidae live in streams and breathe with lateral abdominal gills, and sometimes with additional ventral gill tufts (Corydalus) (Tarter et al., 1975, 1979; Neunzig \& Baker, 1991).

Adults and larvae of Sialidae are comparatively well studied (e.g., Röber, 1942; Czihak, 1953) and the morphology of adults of Corydalus and Chauliodes was treated in detail by Kelsey $(1954,1957)$ and Maki (1936), respectively. The head musculature of a larva assigned to the genus Corydalus was described by Kramer (1955). However, as she did not use histological sections and scanning electron microscopy, and did not describe the nervous system, a study of larvae of Corydalidae (especially Chauliodinae) with modern methods appears desirable. Besides this, since the studies of Röber (1942) and Kramer (1955) a considerable amount of information on neuropterid larval head structures has become available (Wundt, 1961; MacLeod, 1964; Rousset, 1966; Zwick, 1967; Tarter et al., 1979; Paulus, 1986; Grebennikov, 2004; Aspöck \& Aspöck, 2007; Beutel \& Ge, 2008).

The morphological data presented here are discussed with respect to their phylogenetic implications. The aims include the evaluation of the monophyly of Megaloptera, the interrelationships within the order, and the phylogenetic affinities of the group within Neuropterida. The data 


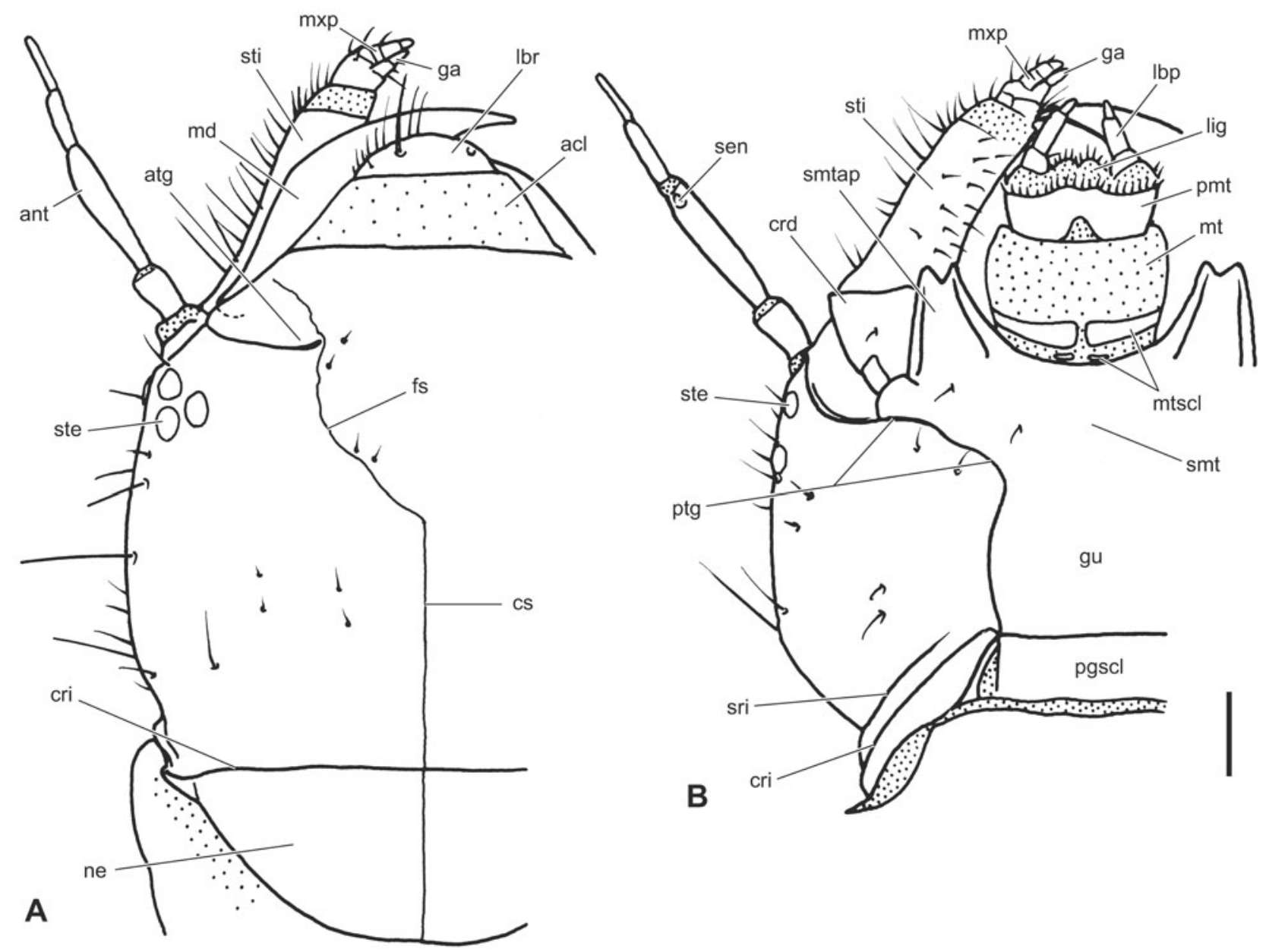

Fig. 1. A-B. Larval head of Neohermes. A - dorsal view; B - ventral view. Abbreviations: acl - anteclypeus; ant - antenna; atg anterior tentorial grooves; crd - cardo; cri - nearly circular ridge delimiting neck region; cs - coronal suture; fs - frontal suture; ga galea; gu - gula; lbp - labial palp; lbr - labrum; lig - ligula, md - mandible; mg - maxillary groove; mt - mentum; mtscl - sclerotisations of mentum; $\mathrm{mx}$ - maxilla; mxp - maxillary palp; ne - neck; pgscl - postgular sclerite; pmt - prementum; ptg - posterior tentorial grooves; sen - sensorium; smt - submentum; smtap - submental apohysis; sri - secondary parietal ridge; ste - stemma; sti stipes. Scale bar: $500 \mu \mathrm{m}$.

are presented in a data matrix, but not analysed cladistically at this stage. Ultimately, they will contribute to an extensive future cladistic analysis of all orders of Endopterygota (see Beutel \& Pohl, 2006).

\section{MATERIAL AND METHODS}

\section{List of taxa examined (fixed in $70 \%$ ethanol unless otherwise noted)}

Megaloptera, Corydalidae, Corydalinae: undetermined specimens from Malaysia (fixation unknown, probably boiling water)

Chauliodinae: Neohermes sp. (FAE = ethanol-formaldehydeacetic acid) (Arizona, USA); Archichauliodes sp. (fixation unknown) (New Zealand); Chauliodes sp. (Texas), undetermined species from Lamington National Park (Queensland Australia) (probably Protochauliodes)

Undetermined corydalid larvae from different locations in Nepal (collected by O. Moog, Austria)

Sialidae: Sialis spp. (FAE) (Germany, Austria)

Raphidioptera, Raphidiidae: Phaeostigma (Phaeostigma) notata (Fabricius, 1781); Raphidiidae sp. (earlier instar, not identified to species level) (FAE) (Germany, Austria)
Neuroptera, Osmylidae: Osmylus fulvicephalus (Scopoli, 1763) (Germany),

Nevrorthidae: Austroneurorthus sp. (fixation unknown, probably $100 \%$ ethanol) (Australia)

Chrysopidae: Chrysopa sp. (FAE) (Germany)

Mecoptera, Nannochoristidae: Nannochorista sp. (Pampel's fluid, Bouin) (Australia)

Boreidae: Boreus sp. (FAE) (Germany)

Panorpidae: Panorpa sp. (FAE) (Germany)

Diptera, Culicidae: Culex sp. (FAE) (Germany)

Bibionidae: Bibio sp. (Germany)

Tipulidae: Tipula sp. (FAE) (Germany)

Siphonaptera, Ceratophyllidae: Ceratophyllus sp. (Canada)

Trichoptera, Rhyacophilidae: Rhyacophila sp. (FAE) (Germany) Hymenoptera, Xyelidae: Xyela sp. (Austria)

\section{Methods}

One specimen of an earlier instar larva of Neohermes sp. was embedded in Araldite, cut at $1.5 \mu \mathrm{m}$ (cross sections) and stained with methylene blue and acid fuchsine. Drawings were made using an ocular grid. For SEM micrographs (FEI ESEM XL 30) specimens were cleaned ultrasonically, dried (critical point) and coated with gold. Three-dimensional reconstructions based on 


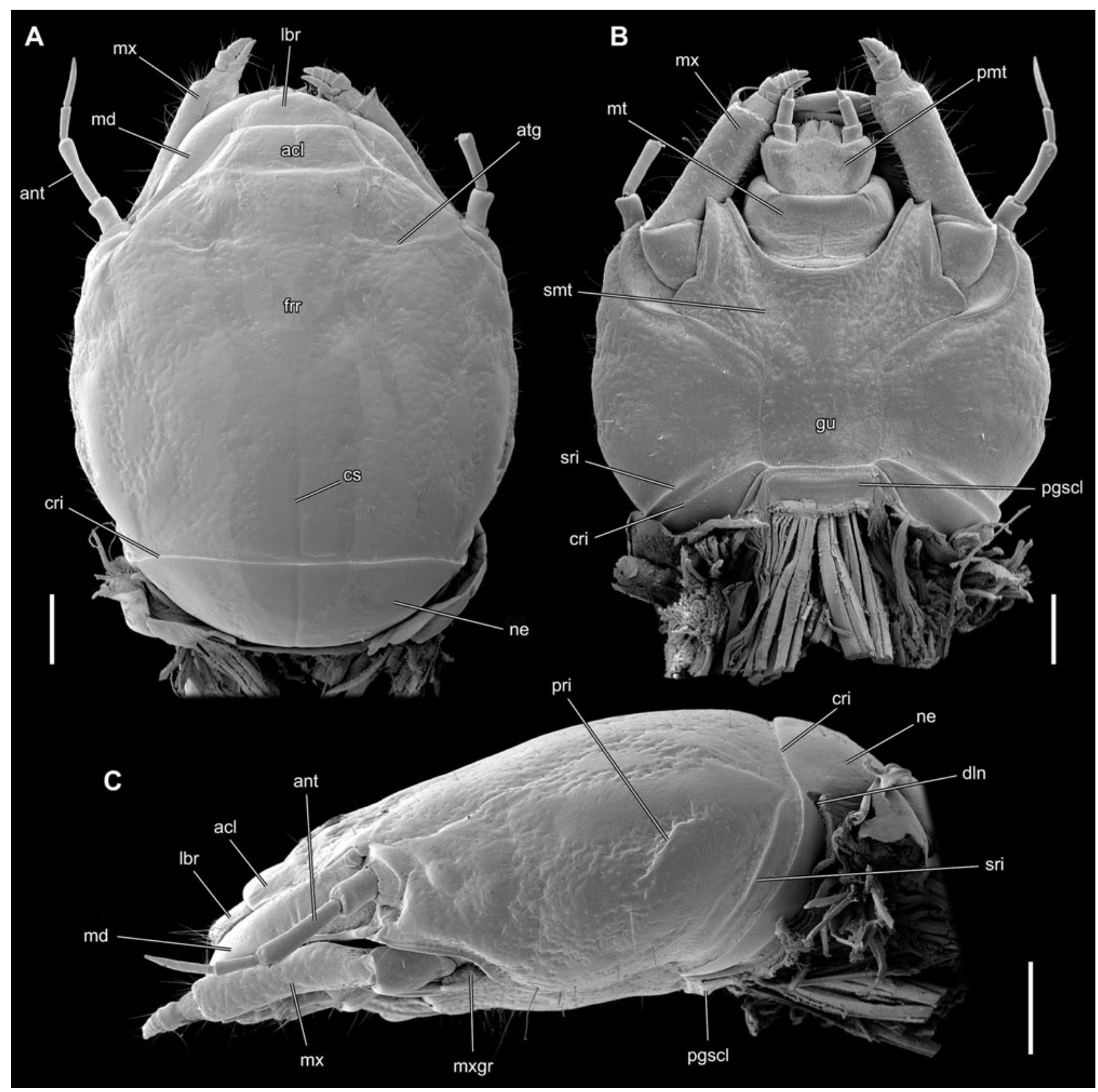

Fig. 2. A-C. SEM micrographs, larval head of Neohermes. A - dorsal view; B - ventral view; C - lateral view. Abbreviations: acl - anteclypeus; ant - antenna; atg - anterior tentorial grooves; cri - nearly circular ridge delimiting neck region; cs - coronal suture; $\mathrm{dln}$ - dorsolateral notch; frr - frontal region; gu - gula; lbr - labrum; lc - lacinia; md - mandible; mt - mentum; mx - maxilla; mxgr - maxillary groove; ne - neck; pgscl - postgular sclerite; pmt - prementum; pri - parietal ridge; smt - submentum; sri - secondary parietal ridge. Scale bar: $500 \mu \mathrm{m}$.

microtome sections were carried out using Alias $^{\circledR}$ Maya $^{\mathrm{TM}} 7$ and Bitplane Imaris ${ }^{\circledR} 5.7$ software.

V. Kéler's nomenclature (v. Kéler, 1963) is used for the musculature.

\section{GENERAL APPEARANCE AND LARVAL HEAD ANATOMY OF NEOHERMES}

\section{General appearance}

Later instars large, total length between $25 \mathrm{~mm}$ and 30 $\mathrm{mm}(\mathrm{n}=10)$. Body elongate and distinctly flattened. Head large (Figs 1, 2). Thorax about half as long as abdomen. Dorsal side of head and thoracic tergites display dis- tinct pattern of brown cuticle and brighter areas. Head, thoracic tergites and prothoracic sternite sclerotised, with smooth and shiny cuticle. Most other parts semimembranous or membranous. All thoracic tergites medially divided by a thin line. Prothorax about twice as long as meso- or metathorax, parallel-sided. Cervix absent. Pleurotergites well developed. Meso- and metatergites subparallel, with very narrow pleurotergites. Abdominal segments more rounded laterally. Unsclerotised tergites I-VIII subdivided by transverse fold, with indistinctly 2-segmented filamentous tracheal gills and cribriform spiracles. Segment IX slightly narrower and longer than 

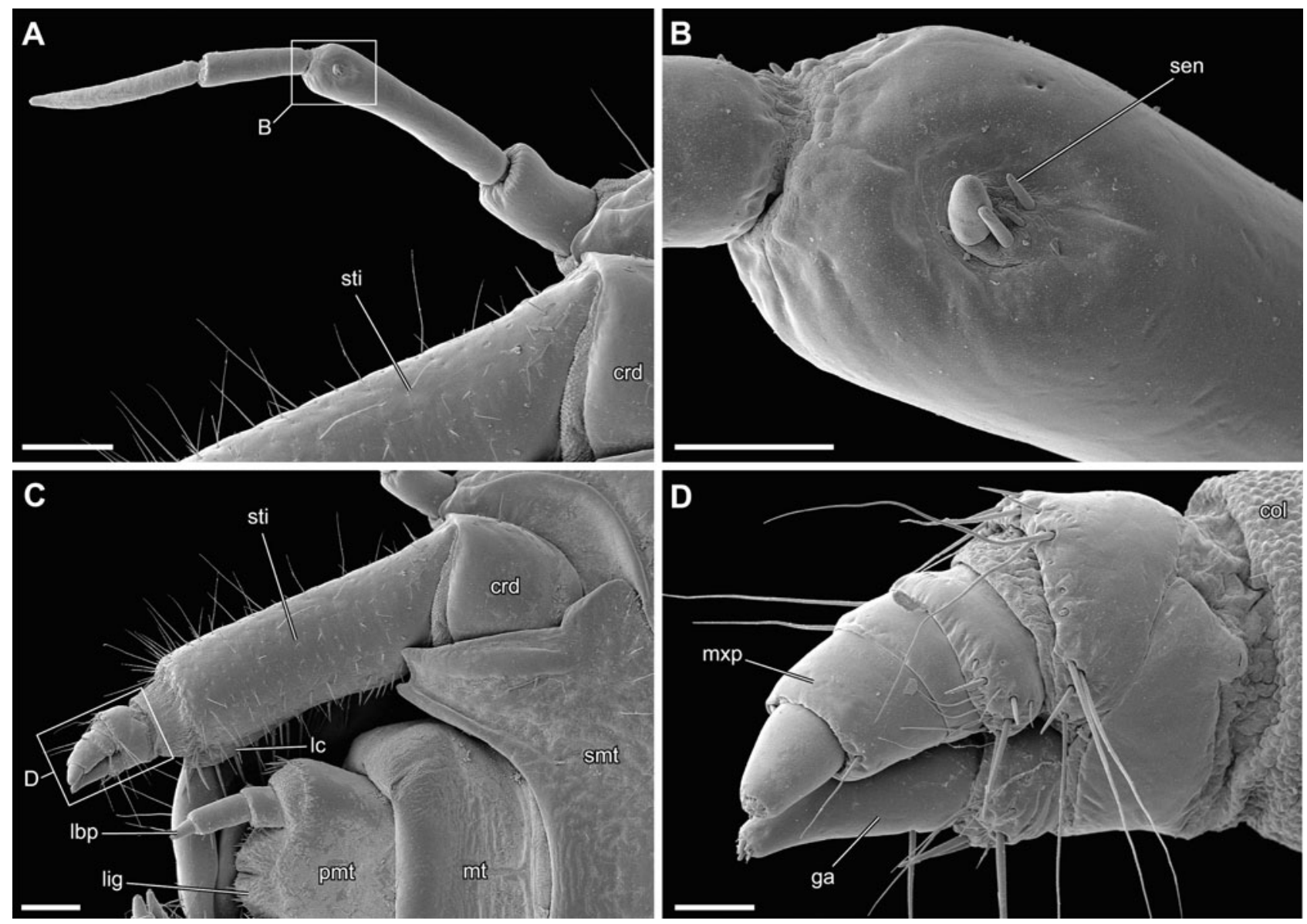

Fig. 3. A-D. SEM micrographs, larval head structures of Neohermes. A - antenna, ventral view; B - penultimate antennomere with sensorium; C - ventral view, mouthparts; D - distal part of maxilla. Abbreviations: col - stipital collar; crd - cardo; ga - galea; lbp - labial palp; lig - ligula; $\mathrm{mt}$ - mentum; mxp - maxillary palp; pmt - prementum; sen - sensillum of second antennomere; smt submentum; sti - stipes. Scale bar: A, C: $200 \mu \mathrm{m}, \mathrm{B}, \mathrm{D}: 50 \mu \mathrm{m}$.

VIII. Segment X with paired anal prolegs with two hooks each and a short 1-segmented filament.

\section{Head capsule, external features (Figs 1, 2)}

Head ca. $4.2 \mathrm{~mm}$ long from dorsal hind margin to anterior clypeal edge; maximum width ca. $3.4 \mathrm{~mm}$. Slightly retracted into prothorax. Colour brown, with brighter areas indicating areas of muscle attachment. Cuticle smooth and shiny. Thin setae of different length distributed on head capsule as shown in Figs 1 and 2. Distinctly prognathous, nearly parallel-sided, very slightly rounded laterally, with rounded temples anterad of constricted neck region. Distinctly flattened; dorsal side only very slightly convex; ventral side flat. Very distinct, almost circular ridge present anterad of neck region; ending at anterolateral edge of postgular sclerite (Figs 1A, 2A: cri, pgscl); additional less distinct secondary parietal ridge present laterally anterad of primary ridge (Fig. 2B, C: sri); dorsal part of neck semicircular, separated from lateral and ventrolateral parts by deep dorsolateral notch serving as attachment area of dorsal head retractors (Fig. 2C: dln). Foramen occipitale only slightly narrowed, transverse and oval. Oblique irregular parietal ridge present on posterior temporal region (Fig. 2C: pri). Six stemmata arranged in curved anterior and posterior rows anterolaterally; anteri- ormost stemma located below antennal base; uppermost stemma reduced, indistinct; corneal lenses only very slightly convex. Trapezoid anterior part of clypeal region unpigmented (anteclypeus), separated from posterior part by very low and medially indistinct internal transverse ridge (Fig. 1A: acl); frontoclypeal suture absent. Frontal region short; frontal suture irregular, roughly lyriform, anteriorly bisecting the lateral postclypeus (Fig. 1A: fs); distinct posteriorly, obliterating anterad of broad, fissureshaped anterior tentorial grooves. Coronal suture (= epicranial stem) distinct, more than half as long as head capsule on dorsal side (Figs 1A, 2A: cs). Median endocarina, hypostomal rods or ventral epicranial ridges absent. Maxillary grooves present but short (Fig. 2C: mxgr), laterally bordered by very distinct curved ridge and mesally by the lateral submental edge. Posteromedian part of head capsule formed by broad, laterally convex gula and short, trapezoid, lightly pigmented postgular sclerite (Figs 1B, 2B, C: pgscl). Fissure-shaped posterior tentorial grooves (Fig. 1B: ptg) scarcely recognisable externally.

\section{Internal skeletal structures (Fig. 5)}

Posterior tentorial arms arise in central area of ventral wall of head capsule with strongly sclerotised, massive basal parts. Connected by anteriorly arched, flat tentorial 


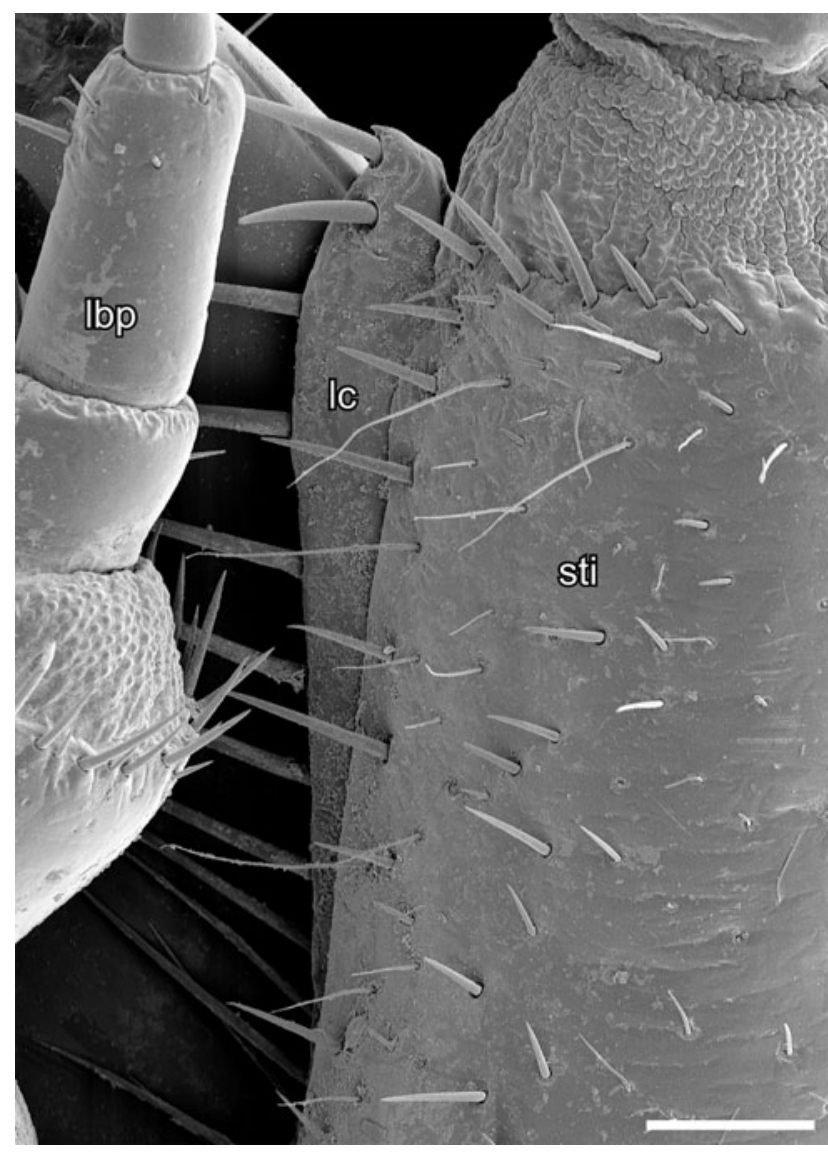

Fig. 4. SEM micrograph, Lacinia and distal part of stipes of Neohermes. Abbreviations: lbp - labial palp; lc - lacinia; sti stipes. Scale bar: $200 \mu \mathrm{m}$.

bridge. Anteriorly continuous with moderately flattened corpora tentorii. Dorsal arms bifurcated. Shorter anterior branch thick and sclerotised. Posterior branch semimembranous, with flattened, horizontal apical part; attached to head capsule with minute fibrillae. Both branches separated by antennal nerve. Anterior arms strongly developed and sclerotised, arising from mesal part of fissure-shaped anterior tentorial grooves.

\section{Labrum (Figs 1A, 2A, 6A, 7B)}

Small, connected with anterior clypeal margin by a membrane. Rounded laterally and anteriorly, with a very shallow anteromedian emargination. Dorsal side with a pair of longer setae. Shorter and longer fine setae inserted along anterior margin. Tormae at posterolateral edge well developed.

Musculature (Figs 8, 9A-E): M. 7: M. labroepipharyngalis (Kramer, 1955 [Corydalus]: cmlr; Röber, 1942 [Sialis]: M.labr.I,II), composed of two subcomponents and numerous fibres, $\mathrm{O}$ (= origin): dorsal wall of labrum, I (= insertion): central and posterior region of ventral wall of labrum (anteriormost part of epipharynx); M. 8: M. frontolabralis (Kramer, 1955: dmlr; Röber, 1942: M.labr.fr.), strongly developed, O: central area of frons, above brain, I: medially on hind margin of dorsal labral wall; M. 9: M. frontoepipharyngalis (Kramer, 1955: lmlr;
Röber, 1942: Mt.), well developed, O: anterolaterad of M. 8 , I: labral tormae with a tendon.

\section{Antenna (Figs 1, 2, 3A, B)}

Four-segmented, slender, less than half as long as length of head capsule. Inserted in a cylindrical membranous socket on a sclerotised articulating area immediately laterad of the secondary mandibular joint. First segment about twice as long as wide, slightly widening distally. Antennomere 2 more than 5 times as long as maximum width, slender basally, gradually widening towards the distal part, slightly narrowing apically; with cupuliform sensillum subapically on ventral side, accompanied by 2 small peg-shaped sensilla and one very small sensillum (Fig. 3B: sen). Antennomere 3 slender, slightly longer than 1. Distal segment very slender, cylindrical, rounded apically, with apical field of minute sensilla.

Musculature (Figs 6A, 9B-D): M. 1: M. tentorioscapalis anterior (Kramer, 1955: man; Röber, 1942: antennal musculature not labelled), O: semimembranous posterior branch of dorsal tentorial arm; I. anteriorly on the base of the scapus, M. 2, 4: Mm. tentorioscapales posterior/medialis (Kramer, 1955: dan, lan), O: posterior branch of dorsal tentorial arm, together with M. 1, I: posterodorsally and posteroventrally on the base of the scapus; M. 5/6: Mm. scapopedicellares lateralis/medialis: absent.

\section{Mandible (Fig. 7C, D)}

Primary (Fig. 7D: co) and secondary mandibular joint well developed. Surface smooth. Outer margin evenly rounded. Slightly asymmetric distally. Apical tooth strongly developed. Three additional teeth arranged in a row on right mandible; four on left mandible; subapical tooth of left mandible blade-like; following tooth strongly pointed. Mesal margin of proximal part of mandibles evenly curved. Prostheca, mola and brushes of hairs absent.

Musculature (Figs 8, 9B-F): M. 11: M. craniomandibularis internus (Kramer, 1955: mdf; Röber, 1942: M.add.mand.), very large muscle, O: extensive areas of the posterodorsal, dorsolateral and ventrolateral head capsule; I: adductor tendon; M. 12: M. craniomandibularis externus (Kramer, 1955: mde; Röber, 1942: M.abd.mand.), O: laterally on the posterior head capsule, anterad of the neck region, I: abductor tendon; M. 13: M. hypopharyngomandibularis (not observed by Kramer [1965] and Röber [1942]), two extremely thin fibres accompanied by a nerve, O: process on the semimembranous anterior part of the dorsal tentorial arm, mesad of the origin of the extrinsic antennal muscles; I: dorsally on the mandibular base. The name of this muscle refers to the origin on ventral hypopharyngeal apophyses in apterygote insects (v. Kéler, 1963).

\section{Maxilla (Figs 1B, 2B, C, 3C, D, 4, 9A)}

Not connected with labium and hypopharynx, movable in lateral direction. Slightly protracted, but inserted in distinct articulatory fossa formed by lateral submental wall and concave genal area below antennal articulatory area (Fig. 3C). Articulatory membrane not visible externally. Cardo large, undivided, with rounded lateral margin. 


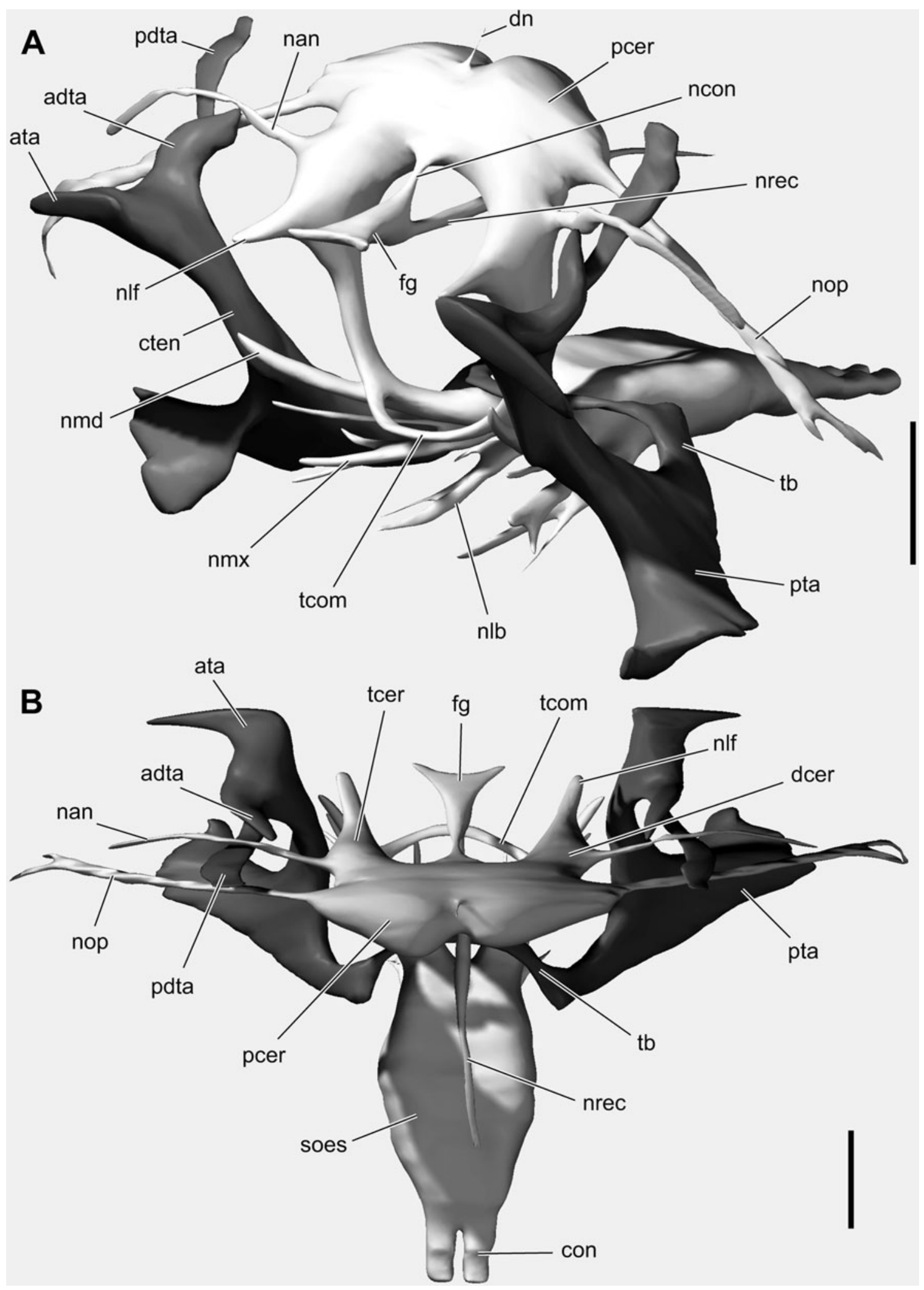

Fig. 5. 3-d reconstructions, brain and tentorium of Neohermes larva. A - anterolateral view; B - dorsal view. Abbreviations: adta - anterior branch of dorsal tentorial arm; ata - anterior tentorial arm; con - connective; cten - corpora tentorii; dcer deutocerebrum; $\mathrm{dn}$ - dorsal nerve; fg - frontal ganglion; nan - nervus antennalis; ncon - nervus connectivus; nlb - nervus labialis; nlf - common base of nervus labralis and frontal connective; nmd - nervus mandibularis; nmx - nervus maxillaris; nop - nervus opticus; nrec - nervus recurrens; pcer - protocerebrum; pdta - posterior branch of dorsal tentorial arm; pta - posterior tentorial arms; soes - suboesophageal ganglion; tb - tentorial bridge; tcer - tritocerebrum; tcom - tritocerebral commisure. Scale bar: $200 \mu \mathrm{m}$. 

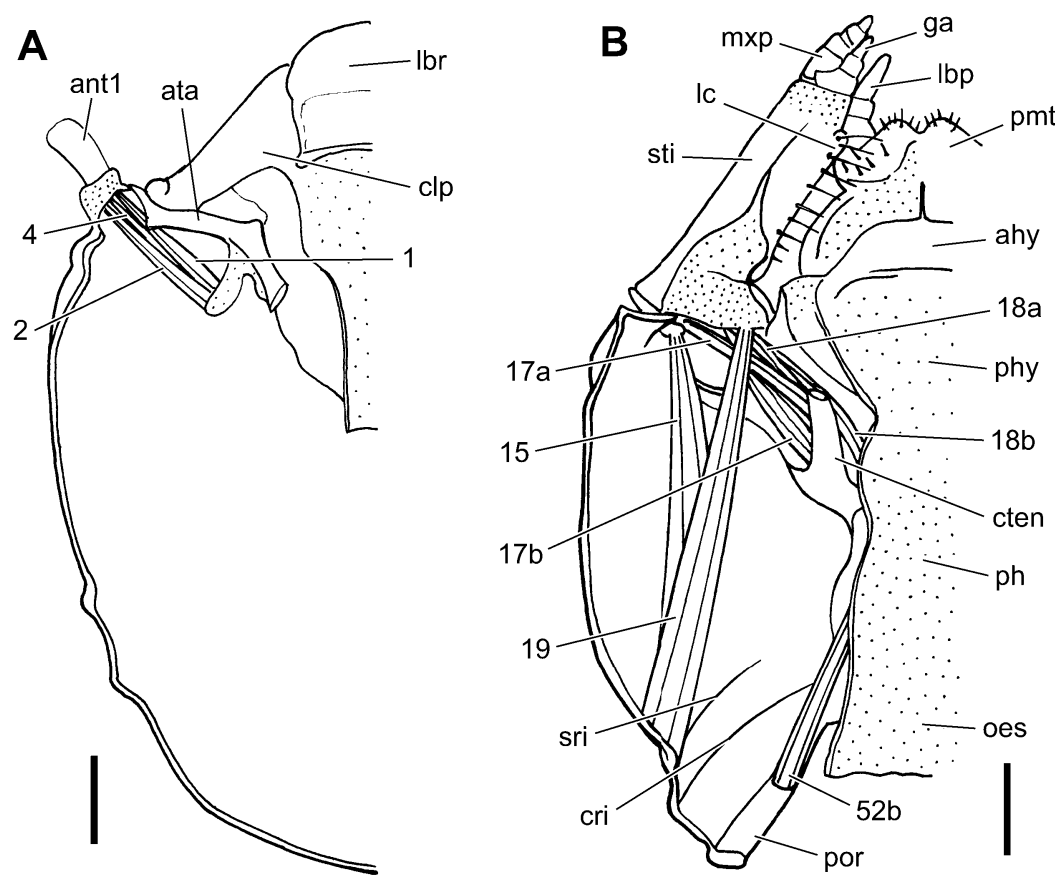

Fig. 6. Larval head of Neohermes, horizontal sections. A - dorsal part; B - ventral part. Abbreviations: ahy - anterior hypopharynx; ant 1 - antennomere 1; ata - anterior tentorial arm; clp - clypeus; cri - nearly circular ridge delimiting neck region; cten - corpora tentorii; ga - galea; lbp - labial palp; lbr - labrum; lc - lacinia; mxp - maxillary palp; oes - oesophagus; ph - pharynx; phy posterior hypopharynx; pmt - prementum; por - postoccipital ridge; sri - secondary parietal ridge; sti - stipes; 1 - M. tentorioscapalis anterior; $2-$ M. tentorioscapalis posterior; $4-\mathrm{M}$. tentorioscapalis medialis; $15-$ M. craniocardinalis; $17 \mathrm{a}, \mathrm{b}-\mathrm{M}$. tentoriocardinalis; $18 \mathrm{a}, \mathrm{b}-\mathrm{M}$. tentoriostipitalis; $19-$ M. craniolacinialis; $52 \mathrm{~b}$ - posterior bundle of M. tentoriopharyngalis. Scale bar: $500 \mu \mathrm{m}$.

Anterior margin nearly straight, connected with stipes by a hinge. Stipes very elongate, forming a tube-like structure together with a prominent mesal edge, which probably represents a partly reduced lacinia (Fig. 4: 1c); both parts entirely fused (stipitolacinia); slightly narrowing towards apex; longer and shorter setae distributed over entire surface; longer setae mainly inserted along lateral margin; apical part membranous. Presumptive lacinia represented by narrow but distinct and sclerotised flattened lobe distally; mesal edge set with long setae; distal setae slightly stronger and apically slightly curved; not recognisable as a separate element proximally (see above). Galea and palp adjacent, inserted on apical membranous part of stipes (Fig. 3D: col). Galea threesegmented; proximal galeomere broad and laterally broadly connected with palpifer; short second galeomere with strong mesally directed seta and a pair of anteriorly directed adjacent setae; other setae as shown in Fig 3C; distal galeomere almost four times as long as wide basally; narrowing distally, apically rounded with a field of minute sensilla. Short, four-segmented palp borne by semicircular palpomere; membrane between palpifer and proximal palpomere widened laterally; palpomere 1 short, with two adjacent mesally directed stronger setae and a transverse row of thinner setae on mesal side; other setae as shown in Fig. 3C; palpomere 2 very short, especially on mesal side, not distinctly separated from following segment; palpomere 3 about as long as wide, slightly narrowing distally; palpomere 4 conical, with group of minute sensilla on flattened apex.
Musculature (Figs 6B, 9): M. 15: M. craniocardinalis (Kramer, 1955: ccm; Röber, 1942: M.rot.ant.max.), well developed, O: ventrolateral wall of head capsule, I: laterally on cardinal base with a tendon; M. 17: M. tentoriocardinalis, composed of two subcomponents, M. 17a (Kramer, 1955: lctm; Röber, 1942: M.add.cd), O: laterally on upper part of corpora tentorii, I: laterally on inner surface of cardo, M. 17b (Kramer, 1955: mctm; Röber, 1942: M.add.cd), O: corpora tentorii, below M. 17a and mesal side of the lateral part of the tentorial bridge, I: mesally on the inner surface of the cardo; M. 18: M. tentoriostipitalis (Kramer, 1955: stm; Röber, 1942: M.add.st), composed of two subcomponents, M. 18a, O: upper part of corpora tentorii, close to M. 17a, and mesal side of the lateral part of the tentorial bridge, I: mesally on a membrane connected with the stipital base, M. 18b, $\mathrm{O}$ : mesal side of the lateral part of the tentorial bridge, together with M. 18b and M. 17b, I: basal part of the stipitolacinia with a thin tendon; M. 19: M. craniolacinialis (Kramer, 1955: 1ctm; Röber, 1942: M.fl.g), O: lateral wall of head capsule, slightly posterad of M. 15, I: mesally on the base of the stipitolacinia; M. 20: M. stipitolacinialis (Kramer, 1955: not listed; Röber, 1942: M.fl.st.lac), O: ventrolaterally on the stipital base, I: dorsal stipitolacinial connecting area by means of a tendon; M. 21: M. stipitogalealis (Kramer, 1955: gsm; Röber, 1942: M.fl.st.lac), O: ventrally on the stipital base, I: ventromesally on the base of galeomere 1; M. 22: M. stipitopalpalis externus (Kramer, 1955: dpm; Röber, 1942: M.abd.p.m), O: stipital base, together with M. 21 and M. 23, I: dorso- 

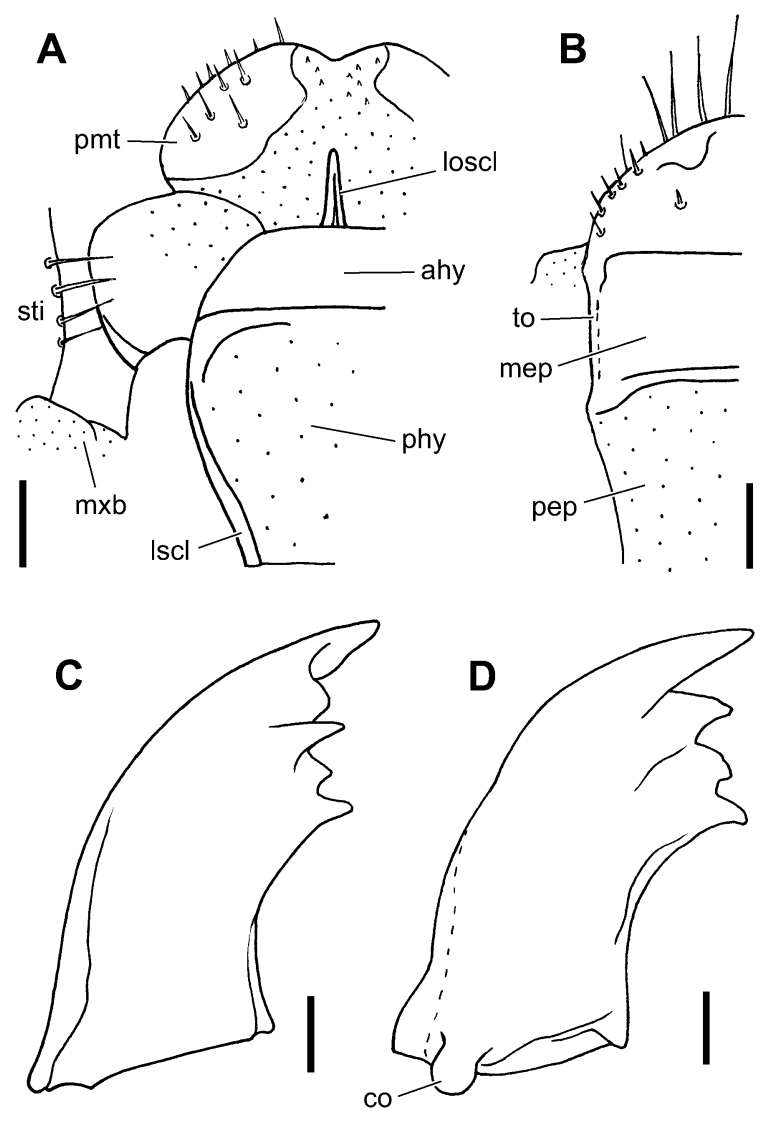

Fig. 7. Larval head structures of Neohermes. A - hypopharynx, dorsal view; B - labrum, ventral view; $\mathrm{C}$ - mandible, dorsal view; D - left mandible, ventral view. Abbreviations: ahy - anterior hypopharynx; co - condyle of primary mandibular joint; loscl - longitudinal salivary sclerite; lscl - lateral sclerotisation of prepharynx; mep - middle section of epipharynx; mxb - maxillary base; pep - posterior section of epipharynx; phy posterior hypopharynx; pmt - prementum; sti - stipes; to - tormae. Scale bar: $250 \mu \mathrm{m}$.

laterally on the base of palpomere 1; M. 23: M. stipitopalpalis internus (Kramer, 1955: vpm; Röber, 1942: M.add.p.m), O: stipital base, between M. 21 and M. 22; I: ventrally on the base of palpomere 1; Mm. 24-27: Mm. palpopalpales primus-quartus, absent.

\section{Labium (Figs 1B, 2B, 3C, 8, 9A)}

Submentum laterally bordered by suture but integrated into ventral wall of head capsule; posteriorly not separated from gula; with two strongly developed lateral lobes, with an angular lateral margin bordering the maxillary groove, and deeply notched anterolateral apices (Figs 1B, 3C). Large, laterally rounded, largely unsclerotised mentum inserted in deep median submental excavation; paired transverse sclerites present on posterior part of mentum, and two very small sclerites posteromesally, immediately close to anterior submental margin; anterior part of mentum membranous. Prementum slightly smaller than mentum, depending on degree of retraction (Figs 2B, 3C); largely sclerotised ventrally, with small posteromedian membranous area; anterior margin of sclerotised part with regular fringe of short spines. Dorsal side largely membranous, but with distinctly sclerotised lateral areas with short spine-like setae. Longitudinal dark sclerotisation with median fissure (longitudinal salivary sclerite in the following; Fig. 7B: lscl) separates dorsal prementum from anterior hypopharyngeal margin. Three-segmented palp inserted on membranous elevation; palpiger not present as sclerotised element; palpomere 1 short, about as long as wide; palpomere 2 elongate, cylindrical; palpomere 3 small, conical, with apical field of minute sensilla. Paraglossae absent. Medially divided, membranous ligula possibly homologous with glossae.

Musculature (Figs 8, 9): M. 28: M. submentopraementalis (Kramer, 1955: rst; Röber, 1942: M.ret.lab), a broad flat muscle, O: medially on the hind margin of the submentum, I: medially on the posterior margin of the mentum; M. 29: M. tentoriopraementalis inferior (Kramer, 1955: vlbm; Röber, 1942: M.ret.praem.lat), O: mesally on the base of the tentorial bridge, I: ventrally on the base of the prementum, close to the median line; M. 30: M. tentoriopraementalis superior (Kramer, 1955: vlbm; Röber, 1942: ventral bundles of M. ret.praem), O: base of the tentorial bridge, together with M. 29, I: laterally on the premental base; M. 31: M. praementoparaglossalis, absent; M. 32: M. praementoglossalis, absent; M. 34: M. praementopalpalis externus (Kramer, 1955: $\mathrm{lbpm}_{1}$; Röber, 1942: M.lev.palp.lab), one bundle, O: ventrolaterally on the premental base, I: ventrally on the base of palpomere I; Mm. 35/36: Mm. palpopalpales labii primus/secundus (Kramer, 1955: $\mathrm{lbpm}_{2}$ ), absent.

\section{Epipharynx (Figs 6A, 7B, 8, 9A)}

Anteriormost epipharynx, i.e. ventral surface of labrum very slightly concave on both sides, thus fitting with the upper surface of the mandible. Fringe of short spines present along anterolateral margin. Cuticle sclerotised, pigmented, with smooth and shiny surface. Middle section of free epipharynx between labral tormae less strongly pigmented, but also sclerotised. Posterior epipharynx anteriorly delimited by indistinct transverse bar or thickening of the cuticle (Fig. 7A). Laterally fused with posterior hypopharynx, thus forming closed, flattened prepharyngeal tube (Figs 8,9B).

Musculature (Fig. 8): M. 43: M. clypeopalatalis (Kramer, 1955: cbm; Röber, 1942: M.cl.ep), strongly developed, composed of four subcomponents and numerous fibres, M. 43a, anterior postclypeal area, I: anterior epipharynx, anterad of functional mouth (opening of prepharygeal tube), M. 43b, separated from M. 43 by first dorsal transverse muscle, O: posteriorly adjacent with origin of M. 43a, I: laterally on the functional mouth, M. $43 \mathrm{c}$, separated from M. 43b by strongly developed second transverse muscle, $\mathrm{O}$ : posteriorly adjacent with origin of M. 43b, I: posterad of M. 43b, M. 43d, separated from M. $43 \mathrm{c}$ by strongly developed third transverse muscle, $\mathrm{O}$ : posteriorly adjacent with origin of M. $43 \mathrm{c}$, I: anterad of anatomical mouth opening.

It cannot be excluded that the posteriormost subcomponent (M. 43d) is homologous with M. clypeobuccalis (M. 44). 


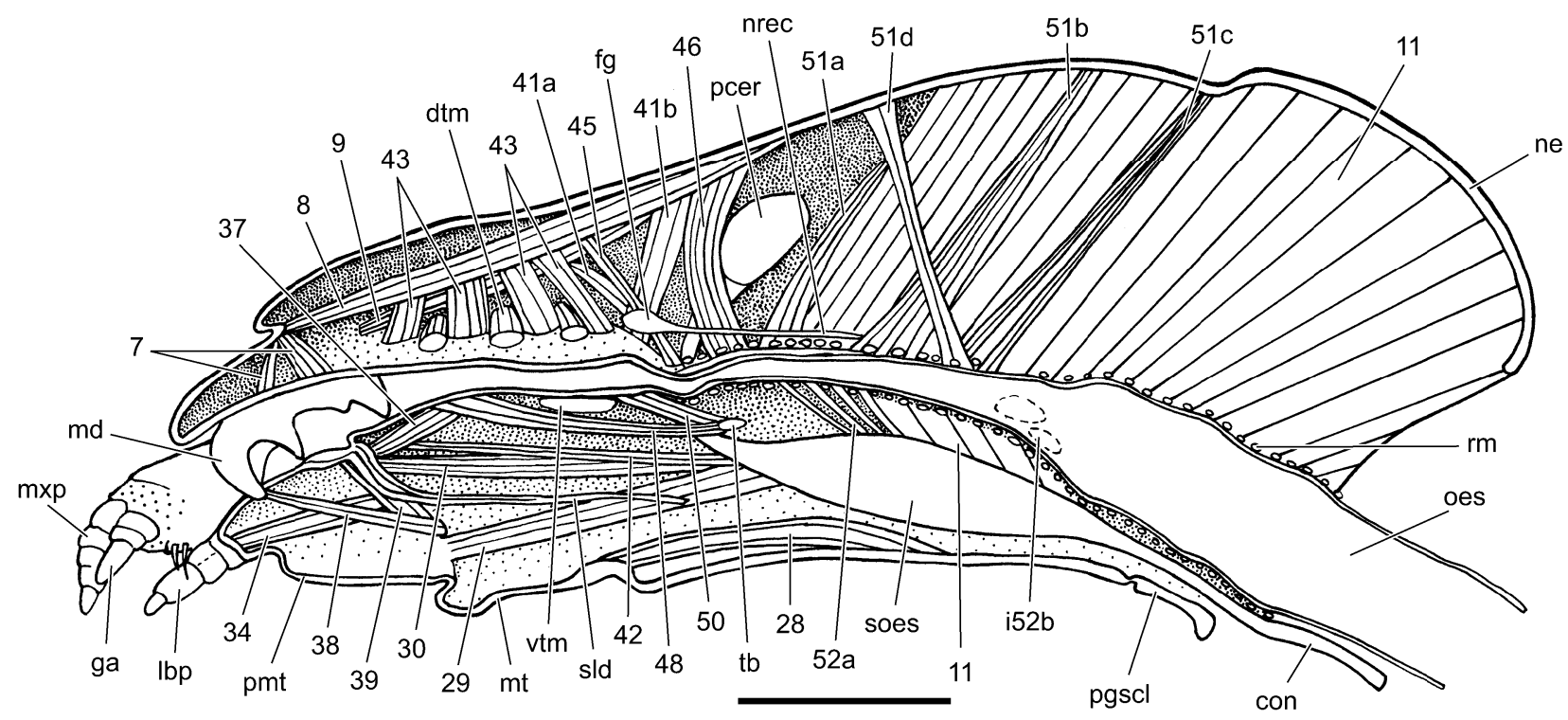

Fig. 8. Larval head of Neohermes, sagittal section. Abbreviations: con - connective; dtm - dorsal transverse muscle; fg - frontal ganglion; ga - galea; lbp - labial palp; md - mandible; $\mathrm{mt}$ - mentum; mxp - maxillary palp; ne - neck; nrec - nervus recurrens; oes - oesophagus; pgscl - postgular sclerite; pmt - prementum; pcer - protocerebrum; rm - ring muscles; sld - salivary duct; soes suboesophageal ganglion; tb - tentorial bridge; vtm - ventral transverse muscle; $\mathrm{i} 52 \mathrm{~b}$ - insertion of anterior subcomponent of $\mathrm{M}$. tentoriopharyngalis posterior; $7-$ M. labroepipharyngalis; 8 - M. frontolabralis; 9 - M. frontoepipharyngalis; 11 - M. craniomandibularis internus; 28 - M. submentopraementalis; 29 - M. tentoriopraementalis inferior; 30 - M. tentoriopraementalis superior; $34-$ M. praementopalpalis externus; 37 - M. hypopharyngosalivarialis; 38/39- Mm. praementosalivariales anterior/posterior; $41 \mathrm{a} / \mathrm{b}-\mathrm{M}$. frontohypopharyngalis; $42-\mathrm{M}$. tentoriohypopharyngalis; $43-\mathrm{M}$. clypeopalatalis; 45/46 - Mm. frontobuccales anterior/posterior; 48/50 - Mm. tentoriobuccales anterior/posterior; 51a-d - M. verticopharyngalis; 52a, b - M. tentoriopharyngalis. Scale bar: $500 \mu \mathrm{m}$.

A strongly developed ventral transverse muscle (vtm) is present anterad of the anatomical mouth.

\section{Hypopharynx (Figs 7A, 8, 9A, B)}

Anterior part forms complex with prementum and mentum. Longitudinal salivary sclerite (see labium) defines border between anterior labium and hypopharynx. Anterior free part of hypopharynx trapezoid, sclerotised and with shiny surface. Separated from posterior part by fairly indistinct transverse sclerotised bar. Posterior hypopharynx laterally fused with posterior epipharynx (see above). Prepharynx laterally reinforced by longitudinal hypopharyngeal sclerotisation (suspensorium).

Musculature (Figs 8, 9B-D): M. 41: M. frontohypopharyngalis, composed of 2 subcomponents, M. 41a (Kramer, 1955: probably $\mathrm{dphd}_{3}$; Röber, 1942: M.ret.ang.o), a slender muscle, O: anterad of anterior tentorial pits, I: mouth angles, immediately laterad of the posterior end of the attachment area of M. 41b, M. 41b (Kramer, 1955: $\mathrm{hphm}$ ), a broad muscle, O: frons, between the origin of M. frontoepipharyngalis (M. 9) and M. frontopharyngalis posterior (M. 46), I: broad attachment on upper edge of posterior prepharynx; M. 42: M. tentoriohypopharyngalis (Kramer, 1955: dlbm; Röber, 1942: dorsal bundle of M. ret.praem), a thin muscle, merges almost completely with M. 30 in its middle section; O: posterolateral edge of the gula, I: low ridge laterad of the opening of the salivary duct.

\section{Pharynx and oesophagus (Figs 8, 9C-F)}

Anterior pharynx broad and flattened (Fig. 9C-D), with very long dorsolateral and shorter ventrolateral folds.
Posterior part roughly H-shaped in cross section, with trilobed dorsolateral folds and bilobed ventrolateral folds (Fig. 9E). Oesophagus distinctly widened, with a helical arrangement of deep longitudinal folds.

Musculature (Figs 8, 9C-F): M. 45: M. frontobuccalis anterior (Kramer, 1955: dphd ${ }_{1}$ [strongly developed]; Röber, 1942: M.front.ph), a thin muscle composed of several very thin fibres, O: anterior frontal region, I: dorsolaterally on the anatomical mouth; M. 46: M. frontobuccalis posterior (Kramer, 1955: $\mathrm{dphd}_{2}$; Röber, 1942: probably represented by M.gen.pariet.ph), composed of several bundles, O: frons, anterad of brain, I: dorsal wall and dorsolateral folds of anterior pharynx; $\mathrm{M}$. 48: M. tentoriobuccalis anterior (Röber, 1942: M.tent.lab), O: tentorial bridge, I: ventral side of floor of prepharyngeal tube, anterad of the ventral transverse muscle; M. 49: M. tentoriobuccalis lateralis (Kramer, 1955: $\mathrm{dphd}_{3}$ ), O: flattened semimembranous anterior part of dorsal tentorial arm, I: dorsolateral fold, laterad of the posterior bundle of M. 46; M. 50: M. tentoriobuccalis posterior (Röber, 1942: M.tent.ph), probably represented by two subcomponents, M. 50a (Kramer, 1955: not listed), a broad and flat median muscle, O: tentorial bridge, together with M. 48, I: ventrally on the prepharyngeal floor, posterad of the ventral transverse muscle, $\mathrm{M}$. 50b (Kramer, 1955: vphd $\mathrm{v}_{8}$ ), strongly developed, O: anterior base of posterior tentorial arm, I: ventrolaterally and laterally on the anterior pharynx, mesad of the circumoesophageal connective; M. 51: M. verticopharyngalis (Kramer, 1955: pphd $_{47}$; Röber, 1942: M.occ.ph.I-III), composed of four subcomponents, M. 51a (Kramer, 1955: 

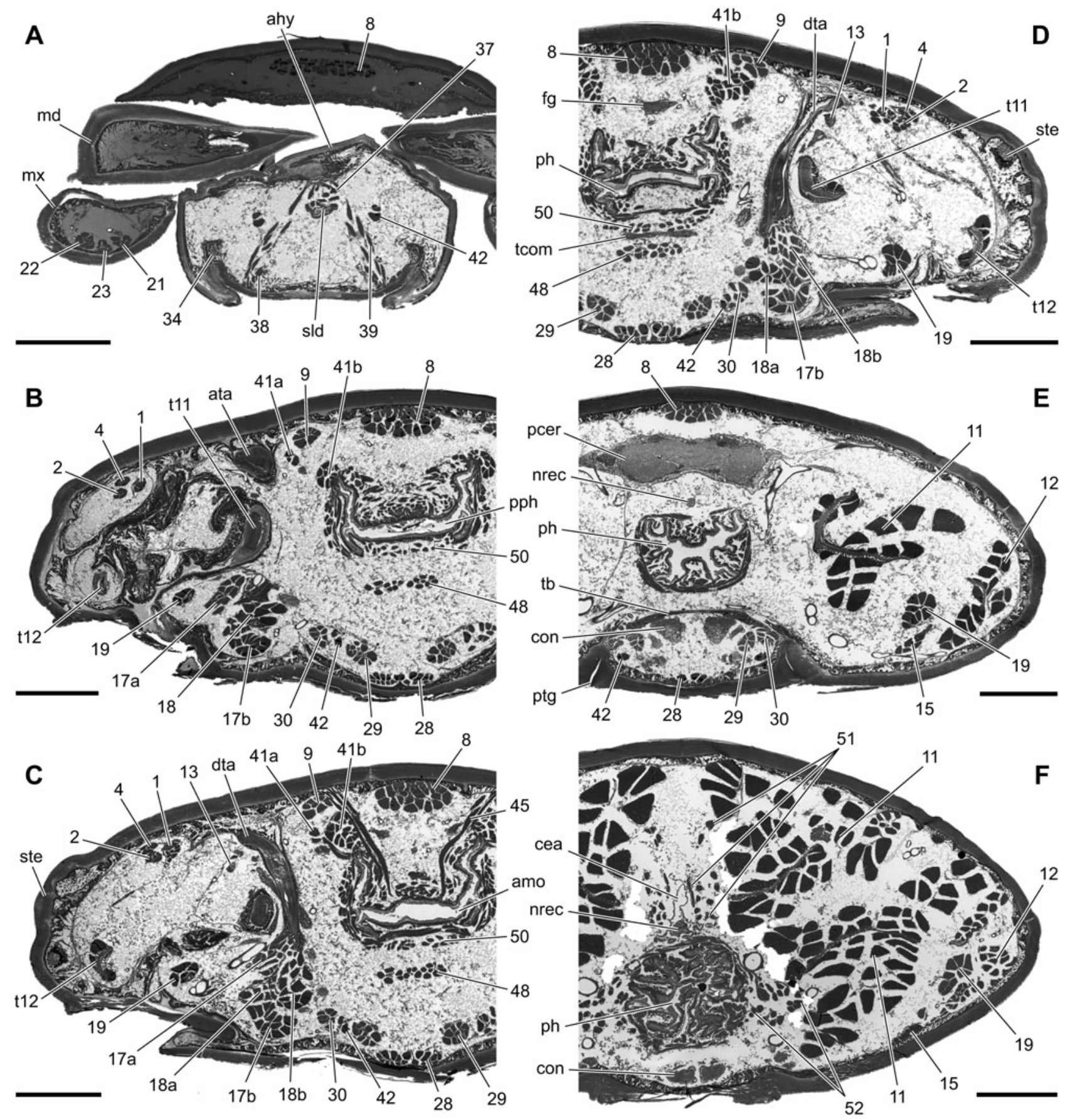

Fig. 9. Larval head of Neohermes, Cross sections. A - anterior clypeal region; B - posterior prepharyngeal region; C - region of anatomical mouth; D - anterior pharyngeal region; $\mathrm{E}$ - region of tentorial base; $\mathrm{F}$ - posterior pharyngeal region. Abbreviations: ahy - anterior hypopharynx; amo - anatomical mouth; ata - anterior tentorial arm; cea - cephalic aorta; con - connective; dta -dorsal tentorial arm; fg - frontal ganglion; $\mathrm{md}$ - mandible; $\mathrm{mx}$ - maxilla; nrec - nervus recurrens; pcer - protocerebrum; ph - pharynx; pph - prepharynx; ptg - posterior tentorial grooves; sld - salivary duct; ste - stemma; tb - tentorial bridge; tcom - tritocerebral commissure; $\mathrm{t} 11$ - tendon of M. craniomandibularis internus; t12 - tendon of M. craniomandibularis externus; $1 / 2 / 4$ - Mm. tentorioscapales anterior/posterior/medialis; 8 - M. frontolabralis; 9 - M. frontoepipharyngalis; 11/12 - Mm. craniomandibulares internus/externus; 13 - M. tentoriomandibularis; $15-$ M. craniocardinalis; 17a, b - M. tentoriocardinalis; 18a, b - M. tentoriostipitalis; $19-$ M. craniolacinialis; 21 - M. stipitogalealis; 22/23 - Mm. stipitopalpales externus/internus; 28 - M. submentopraementalis; 29/30 - Mm. tentoriopraementales inferior/superior; 34 - M. praementopalpalis externus; 37 - M. hypopharyngosalivarialis; 38/39 - Mm. praementosalivariales anterior/posterior; 41a, b - M. frontohypopharyngalis; $42-\mathrm{M}$. tentoriohypopharyngalis; 45 - M. frontobuccalis anterior; 48/50 - Mm. tentoriobuccales anterior/posterior; $51-\mathrm{M}$. verticopharyngalis; $52-\mathrm{M}$. tentoriopharyngalis. Scale bar: 250 $\mu \mathrm{m}$.

pphd $_{5}$; Röber, 1942: M.occ.ph.I), O: laterally on anterior vertex, between attachment areas of anterodorsal bundles of M. 11, I: dorsolaterally on the anterior postcerebral pharynx; M. 51b (Kramer, 1955: pphd 6 ; Röber, 1942: 

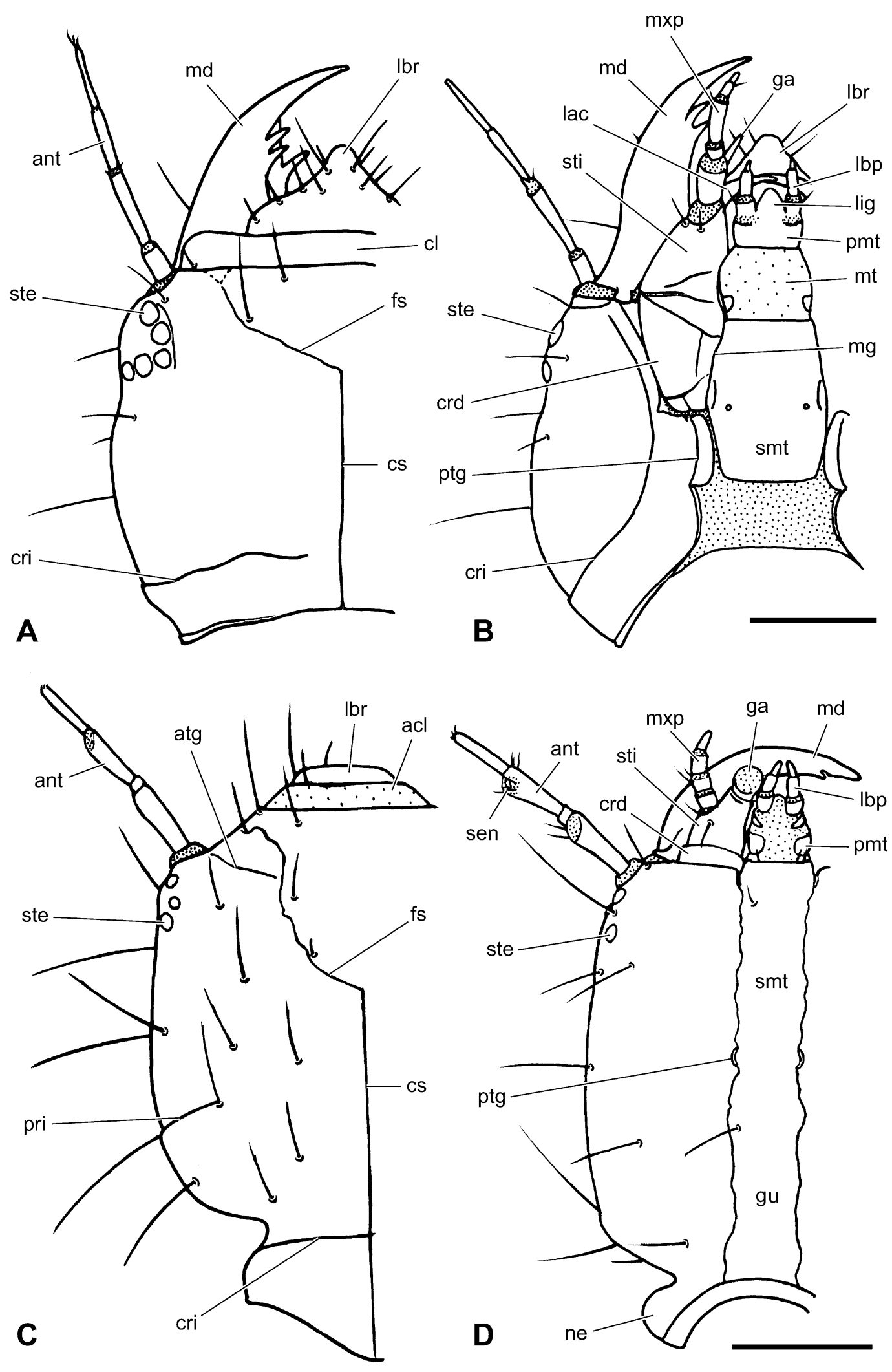

Fig. 10. A-B. Larval head of Sialis. A - dorsal view; B - ventral view. C-D. Larval head of Phaeostigma notata. A - dorsal view; B - ventral view. Abbreviations: acl - anteclypeus; ant - antenna; atg - anterior tentorial grooves; cl - clypeus; crd - cardo; cri nearly circular ridge delimiting neck region; cs - coronal suture; fs - frontal suture; ga - galea; gu - gula; lac - lacinia; lbp - labial palp; lbr - labrum; lig - ligula, md - mandible; $\mathrm{mg}$ - maxillary groove; $\mathrm{mt}$ - mentum; mxp - maxillary palp; ne - neck; pmt - prementum; pri - parietal ridge; ptg - posterior tentorial grooves; sen - sensorium; smt - submentum; ste - stemma; sti - stipes. Scale bar: $500 \mu \mathrm{m}(\mathrm{A}, \mathrm{B}), 200 \mu \mathrm{m}(\mathrm{C}, \mathrm{D})$. 
M.occ.ph.II), several thin bundles, diverging towards insertion, $\mathrm{O}$ : posterior vertex, close to median line, I: postcerebral pharynx; M. 51c (Kramer, 1955: pphd 7 Röber, 1942: M.occ.ph.III), several thin bundles, O: posterior vertex, immediately anterad to ridge delimiting dorsal part of neck region, I: postcerebral pharynx, posterad of M. 51b; M. 51d (Kramer, 1955: ctph?; Röber, 1942: not present in Sialis), a single bundle, O: anterior vertex, close to median line, I: postcerebral pharynx, between the bundles of M. 51c; M. 52: M. tentoriopharyngalis (Kramer, 1955: vphd 8 $_{8-10}$; Röber, 1942: M.postgen.ph), two strongly developed subcomponents, M. 52a, O: ventral wall of head capsule, posterad of tentorial base, I: ventrolaterally on the anterior postcerebral pharynx; M. 52b, composed of numerous thin bundles, $\mathrm{O}$ : ventrolaterally on the postoccipital ridge, I: laterally on the postcerebral pharynx, posterad of the posteriormost bundle of M. 51c.

\section{Salivarium (Figs 7A, 8, 9A)}

Represented by fold between dorsal side of prementum and anterior hypopharyngeal margin, longitudinal salivary sclerite, and distinctly reduced salivary tube. Salivary tube opens on posterior part of fissure of salivary sclerite (see above). Distal unpaired part of duct vertical and sclerotised, with thick walls. Paired salivary tubes extremely thin (diameter ca. $10 \mu \mathrm{m}$ ) without recognisable lumen, difficult to identify on sections of the posterior head region. Salivary glands not present within head capsule (see below).

Musculature (Figs 8, 9A): M. 37: M. hypopharyngosalivarialis (Kramer, 1955: sdm; Röber, 1942: absent in Sialis), strongly developed, composed of many thin fibres, O: dorsolaterally on the hypopharynx, below the functional mouth, I: posteriorly on the distal section of the salivary duct, immediately close to the opening; M. 38: M. praementosalivarialis anterior (Kramer, 1955: cplb; Röber, 1942: see following muscle), moderately sized muscle, $\mathrm{O}$ : posterior margin of prementum, mesad of the insertion of $\mathrm{M}$. tentoriopraementalis inferior, I: anterior margin of salivary sclerite; M. 39: M. praementosalivarialis posterior (Kramer, 1955: cplb; Röber, 1942: prementosalivary muscles probably represented by M.dors.ventr.lab), composed of many thin fibres, O: posterior margin of prementum, together with M. 38, I: salivary sclerite, immediately posterad of opening of salivary tube; M. 40: M. annularis salivarii, absent.

\section{Cerebrum, suboesophageal complex and frontal ganglion (Figs 5, 8, 9)}

Brain very small in relation to head size. Protocerebrum dumbbell-shaped. Simple corpora pedunculata and central body present. Two small separate optic neuropils recognisable. Well developed nervus connectivus originates anteromedially (Fig. 5A: ncon), very thin nerve with unclear homology dorsomedially (Fig. 5A: dn), and thick optical nerves laterally (Fig. 5: nop). Deuto- and tritocerebrum (Fig. 5B: dcer, tcer) together form anteriorly directed conical structure with common base of frontal connective and nervus labralis arising apically (Fig. 5: nlf). Well developed antennal nerve originates on deutocerebrum laterally (Fig. 5: nan), separating both branches of dorsal tentorial arm. Tritocerebral commissure distinct. Circumoesophageal connectives elongate and slender. Suboesophageal complex slender, located in gular region, not reaching hind margin of head capsule posteriorly.

\section{Circulatory system (Fig. 9E)}

Cephalic aorta extremely thin-walled and laterally compressed in the posterior head region. Anterior part dorsoventrally flattened, enclosing nervus recurrens (Fig. 9E: cea). Opens below hind margin of brain.

\section{Glands}

Not present within head capsule.

\section{Fat body}

Absent in specimens examined.

\section{MEGALOPTERAN CHARACTERS OF PHYLOGENETIC RELEVANCE}

The characters are listed in a morphology based sequence (see results). Presumably plesiomorphic character states are coded as (0). The polarity determination is preliminary as it is not based on a cladistic analysis.

1. (omp) Orientation of mouthparts: (0) orthognathous; (1) subprognathous; (2) prognathous, head horizontal, dorsal and ventral wall of head capsule nearly horizontal. The head is distinctly prognathous in Corydalidae (Fig. 1C), Raphidioptera (Fig. 10C, D; Aspöck \& Aspöck, 1971; Aspöck et al., 1991, Figs 54, 62; Beutel \& Ge, 2008), Neuroptera (Wundt, 1961; MacLeod, 1964; Rousset, 1966; Zwick, 1967; Grebennikov, 2004), and several groups of Coleoptera (e.g., Beutel, 1993, 1999). It is subprognathous in larvae of Sialis (Röber, 1942), and this is also the case in many groups of Coleoptera (e.g., Staphylinoidea [partim]; Beutel \& Molenda, 1997) and in larvae of some other groups of Endopterygota (e.g., Kristensen, 2003; Kramer, 1954). An orthognathous condition is found in symphytan larvae (Smith \& Middlekauff, 1987), in "non-spicipalpian" Trichoptera (Winkler, 1959), in many groups of Ditrysia (Kristensen, 2003), and in few groups of Coleoptera (e.g., Chrysomelidae; Lawson, 1991). We also consider the head of larvae of Mecoptera (excl. Nannochoristidae) as orthognathous (Byers, 1987: Figs 24.1, 24.6, 24.8; Bierbrodt 1942: "beiden gemeinsam ist nur die orthognathe Stellung"), even though the head may be lifted to a considerable degree (P. Švácha, pers. comm.).

2. (pri) Parietal ridge: (0) absent; (1) present. A parietal ridge is present in larvae of Corydalidae (irregular in Neohermes; Fig. 2C: pri) and Raphidia (Fig. 10C: pri; Beutel \& Ge, 2008). It is absent in larvae of Sialis (Fig. 10A; Röber, 1942: Fig. 2), Neuroptera (Crampton, 1921; Wundt, 1961; Rousset, 1966), and also in other groups of endopterygote insects (e.g., Smith \& Middlekauff, 1987; Wiggins, 1987; Byers, 1987; Kristensen, 2003). The distinctness varies between different representatives of Corydalidae but clearly defined char- 
acter states cannot be assigned to Corydalinae and Chauliodinae.

3. (nre) Neck region: (0) absent; (1) present. The distinct neck region of larvae of Corydalidae (Figs 1, 2; Crampton, 1921), Raphidioptera (Fig. 10C, D; Aspöck et al., 1991: Figs 53-55, 61-63; Beutel \& Ge, 2008), and Nevrorthidae (Zwick, 1967) is either an apomorphic feature which has evolved several times independently or a groundplan feature of Neuropterida, with secondary reduction in Sialidae and most groups of Neuroptera (suborder Hemerobiiformia in Aspöck et al., 2001; Rousset, 1966). A narrow neck region is also present in some beetle larvae (e.g., Gyrinidae [partim], Dytiscidae [partim]; Beutel, 1993), but is generally absent in other groups of Endopterygota.

4. (cri) Circular ridge: (0) absent; (1) present. A distinct ridge anterad of the neck region is present in larvae of Megaloptera (Figs 1, 2, 10A, B: cri) and Raphidioptera (Fig. 10C, D: cri) (Aspöck et al., 1991: Figs 53, 54), but is absent in Nevrorthidae (Zwick, 1967). It ends at the anterolateral edge of the pregular sclerite in Neohermes (Fig. 1B: cri, pgscl) but extends far anterad in Sialis, where it almost reaches the primary mandibular joint (Fig. 10B).

5. (gul) Gula: (0) not developed as a sclerotised structure or absent; (1) undivided, laterally delimited by a distinct gular suture; (2) undivided, gular suture absent or very indistinct, firmly integrated into ventral wall of capsule; (3) medially divided sclerotised gulasubmentum; (4) strongly narrowed gula. A broad gula laterally delimited by a distinct suture is present in Corydalidae (Figs 1B, 2B; Crampton, 1921) and Nevrorthidae (Zwick, 1967). The gula is more elongate and narrow and almost completely fused with the ventral wall of the head capsule in Raphidioptera (Fig. 10D: gu; Aspöck et al., 1991: Figs 55, 63; Beutel \& Ge, 2008) and triangular and distinctly reduced in size in neuropteran larvae of the myrmeleontoid type as defined by MacLeod (1964). A large larval gula is interpreted as a groundplan feature of Neuropterida in Aspöck et al., 2001. A clearly delimited gular sclerite is also found in some groups of Coleoptera (Beutel, 1993, 1999) and Trichoptera (partim; Malicky, 1973: Figs 26, 30), and also in Ceratophyllus (Siphonaptera; pers. obs. Beutel). The gula is strongly narrowed in most adephagan and hydrophiloid larvae (e.g., Beutel, 1993, 1999). A roughly parallel-sided, medially divided gulasubmentum is present in Nannochoristidae (Pilgrim, 1972). A semimembranous posteromedian area is present in Sialis (Röber, 1942) and presumably basal groups of Coleoptera (Beutel \& Hörnschemeyer, 2002a, b) (coded as 0). A ventral closure is completely absent in symphytan larvae (Parker, 1935), in Boreus, in primary larvae of Strepsiptera (Pohl, 2000), and usually also in neuropteran larvae of the hemerobioid type (e.g., Osmylidae, Chrysopidae; Wundt, 1961; MacLeod, 1964).

6. (hyb) Hypostomal bridge: (0) absent; (1) present. A hypostomal bridge is absent in Megaloptera, in Raphidioptera, in Nevrorthidae, and in neuropteran larvae of the hemerobioid type (Wundt, 1961; Rousset, 1966; MacLeod, 1964), whereas lateral parts of the head capsule meet ventromedially in the neuropteran larvae of the myrmeleontoid type (MacLeod, 1964) and some other groups of Endopterygota (e.g., Micropterigidae, Trichoptera partim; Hasenfuss \& Kristensen, 2003; Winkler, 1959).

7. (pms) Postgular sclerite: (0) absent; (1) present. A transverse unpaired postgular sclerite is present in all corydalid larvae examined (Figs 1B, 2B). This is a potential autapomorphy of the family. The sclerite is absent in Sialis (Röber, 1942: Fig. 2), Raphidia (Beutel \& Ge, 2008) and Neuroptera (Wundt, 1961; Rousset, 1966; Zwick, 1967) and also in other groups of Endopterygota (e.g., Crampton, 1921).

8. (ptg) Posterior tentorial grooves: (0) close to hind margin of head capsule; (1) extending between anterior margin of unsclerotised ventromedian closure of head capsule and hind margin of cardo; (2) strongly shifted anteriorly, widely separated from foramen occipitale. The posterior tentorial grooves are strongly shifted anteriorly in Corydalidae (Fig. 1B: ptg; Kramer, 1955), Raphidioptera (Fig. 10D: ptg; Beutel \& Ge, 2008), Nevrorthidae, and in the myrmeleontid type larvae of Neuroptera (MacLeod, 1964). A similar position is present in many groups of Coleoptera (Beutel, 1993, 1999; Beutel \& Molenda, 1997). An intermediate condition is found in Sialis (Fig. 10B: ptg), where the elongate posterior grooves extend between the anterior margin of unsclerotised ventromedian closure of the head capsule and the hind margin of the cardo. They are close to the foramen occipitale or adjacent to it in the neuropteran larvae of the hemerobioid type (Wundt, 1961; MacLeod, 1964, Rousset, 1966) and in other endopterygote lineages (e.g., Crampton, 1921; Bierbrodt, 1942; Beutel et al., 2008).

9. (dta) Dorsal tentorial arm: (0) present; (1) absent. The dorsal tentorial arm is present and distinctly developed in Corydalidae (Figs 5, 9C, D; Kramer, 1955), Raphidia (Beutel \& Ge, 2008), Neuroptera (partim; e.g., Osmylidae; Wundt, 1961; Chrysopidae; Rousset, 1966; Nevrorthidae; pers. obs. Friedrich), Coleoptera (major part; e.g., Beutel, 1993, 1999; but see Beutel, 1995 and Beutel \& Hörnschemeyer, 2002a, b), Xyela (Beutel et al., 2008), Tenthredinidae (Parker, 1935), and basal groups of Lepidoptera (Kristensen, 1984, 2003). In contrast to Röber (1942) it is present even though very thin in Sialis. It is absent in Strepsiptera (Pohl, 2000), Trichoptera (partim; Winkler, 1959: Fig. 11), Glossata (Kristensen, 2003), Nannochoristidae (N. Kristensen, pers. comm.), Siphonaptera (Sharif, 1937; Widhalm-Finke, 1974), and in Diptera (Cook, 1949; Hennig, 1973), with the possible exception of Olbiogaster (Anthon, 1943). Interestingly, a thin ligament-like structure is retained in Panorpa (Bierbrodt, 1942: Fig. 16, L.M.d.sc; N. Kristensen, pers. comm.). It serves as attachment area of the single extrinsic antennal muscle.

10. (bdt) Bifurcation of dorsal tentorial arm: (0) absent; (1) present. The presence of two apical parts of 
the dorsal tentorial arm (Fig. 5; Kramer, 1955: Fig. 5) is a potential autapomorphy of Corydalidae.

11. (lso) Light sense organs: (0) compound eyes; (1) several stemmata; (2) single eye spot. Stemmata, i.e. specific separated lateral eyes are present in larvae of Corydalidae and in most other neuropterid larvae (e.g., MacLeod, 1964; Paulus, 1986; Tauber, 1991 [reduced in Ithonidae; Grebennikov, 2004]). They are also present in Strepsiptera (first instar larvae; Pohl, 2000), and very likely in the groundplan of Coleoptera (e.g., Beutel, 1993, 1995, 1999), Trichoptera (Wiggins, 1987), and Lepidoptera (Stehr, 1987; Kristensen, 2003). Modified compound eyes occur in larvae of some basal groups of Hymenoptera (with unicorneal lens) and in Mecoptera (with some exceptions; Melzer et al., 1994). Larvae of Siphonaptera are eyeless and this condition is also common in Diptera.

12. (nst) Number of functional stemmata: (0) seven; (1) six; (2) five; (3) four; (4) three; (5) two; (6) one. Six fully developed stemmata are present in Megaloptera (Röber, 1942; Kramer, 1955; Paulus, 1986; Neunzig \& Baker, 1991), Sisyridae, Hemerobiidae (partim; Tauber, 1991), Mengenilla (Strepsiptera; Pohl, 2000), Adephaga (major part; e.g., Beutel, 1993), and in larvae of some groups of Lepidoptera (Stehr, 1987). An additional, reduced stemma occurs in megalopteran and neuropterid larvae (Paulus, 1986). Seven or six stemmata occur in Raphidiidae (Paulus, 1986; Tauber, 1991) and the presence of only four is probably an autapomorphy of Inocelliidae. Seven stemmata do also occur in some groups of Neuroptera (e.g., Myrmeleontidae, Ascalaphidae; Tauber, 1991), and Trichoptera (stemmata closely aggregated; Wiggins, 1987), and this is the maximum number in Endopterygota. Five stemmata occur in many groups of Polyphaga, in Strepsiptera (e.g., Eoxenos; Pohl, 2000), and in some groups of Trichoptera and Lepidoptera (e.g., Micropterigidae; Davis, 1987). A high degree of reduction or complete loss of stemmata occurs in many groups of Endopterygota (e.g., Grebennikov, 2004; Beutel \& Hörnschemeyer, 2002a, b; Davis, 1987).

13. (lbr) Articulation of labrum: (0) labrum free; (1) labrum fused with clypeus. The labrum is movably attached to the clypeus in Corydalidae (Figs 1A, 2A, 8) as in Sialidae (Fig. 10A: lbr) and Raphidioptera (Fig. 10C: lbr), and in most other groups of Endopterygota (e.g., Crampton, 1921; Röber, 1942; Beutel \& Ge, 2008; Beutel \& Hörnschemeyer, 2002a, b; Smith \& Middlekauff, 1987; Wiggins, 1987; Kristensen, 2003; Cook, 1949; Sharif, 1937). It is fused with the head capsule in larvae of Neuroptera (Wundt, 1961; MacLeod 1964), in different lineages of Coleoptera (Beutel, 1993, 1995; Beutel \& Molenda, 1997), and in primary larvae of Strepsiptera (Pohl, 2000).

14. (8) M. frontolabralis: (0) absent; (1) present. M. frontolabralis occurs in Megaloptera (Figs 8, 9A-E; Röber, 1942; Kramer, 1955), in Raphidia (Beutel \& Ge, 2008), and in most other groups of Endopterygota (e.g., Röber, 1942; Winkler, 1959; Kramer, 1954; Sharif, 1937). It is absent in Neuroptera (Myrmeleontidae,
Osmylidae; Korn, 1943; Wundt, 1961; Rousset, 1966), Coleoptera (Das, 1937; Beutel, 1993, 1995, 1999; Beutel \& Hörnschemeyer, 2002a, b), Strepsiptera (Pohl, 2000), and in Lepidoptera with the exception of Micropterigidae (Kristensen, 2003).

15. (9) M. frontoepipharyngalis: (0) present, inserted on tormae; (1) present, inserted on anterior epipharynx, close to the median line; (2) absent. M. frontoepipharyngalis is well developed in Megaloptera (Figs 8, 9B-D; Kramer, 1955; Röber, 1942) as in larvae of most other endopterygote lineages (e.g., Das, 1937; Rousset, 1966: mlrp; Beutel \& Ge, 2008). It is absent in larvae of Mecoptera (excl. Nannochorista; Bierbrodt, 1942; Beutel, pers. obs.), in larvae of some groups of Coleoptera (Beutel, 1993, 1995, 1999), and in primary larvae of Strepsiptera (Pohl, 2000).

16. (ans) Number of antennal segments: (0) multisegmented; (1) 5-7; (2) 4; (3) 3; (4) less than 3; (5) vestigial, no segmentation recognisable. The antenna is composed of four segments in Neohermes (Figs 1, 2, 3A), Archichauliodes (New Zealand) and in Sialis (Fig. 10A), but of five in the larvae assigned to Corydalus by Kramer (1955) (see also Crampton, 1921: Fig. 15) and in the Malaysian species examined. The higher number is apparently due to a subdivision of the apical segment. Five segmented antennae do also occur in Ithonidae (New, 1991) and in some symphytan larvae (Smith \& Middlekauff, 1987). The antenna is 4-segmented in Raphidia (Fig. 10C) and very likely in the groundplan of Coleoptera (Cupedidae, Adephaga; Beutel, 1993; Beutel \& Hörnschemeyer, 2002b). Three antennomeres are present in Chrysopidae and other groups of Neuroptera (MacLeod, 1964; New, 1991), in most polyphagan larvae (e.g., Beutel, 1995, 1999), in most groups of Mecoptera (Pilgrim, 1972; Byers, 1987), and in several groups of Lepidoptera (groundplan, e.g., Micropterigidae, Heterobathmioidea; Kristensen, 2003). Multisegmented antennae as they are found in some groups of Neuroptera (e.g., Nevrorthidae, Osmylidae; Wundt 1961; New, 1991) are probably due to a secondary subdivision of the penultimate antennomere. However, it cannot be fully excluded that this is an ancestral condition. Less than three segments are present in Boreidae (Byers, 1987), Siphonaptera (Sharif, 1937), Trichoptera, Agathiphagidae (Kristensen, 1984, 2003), and in basal groups of Diptera (e.g., Foote, 1991).

17. (sap) Antennal sensorial appendage: (0) absent; (1) present on apical part of antennomere 2; (2) present on apical part of antennomere 3. A peg-like sensorial appendage accompanied by minute spine-like structures is present on the apical part of antennomere 2 (antepenultimate segment) of Neohermes (Figs 1B: sen, 3B) and also in Archichauliodes. Only spine-like structures are present in the Malaysian corydalid species. A peg-like sensorium was not described for Corydalus by Kramer (1955) and for Sialis by Röber (1942). It is present as a spine-shaped structure on segment 2 of the Sialis larvae we examined (Fig. 10B). It is conceivable that the insertion on the antepenultimate segment, which is pos- 
sibly the result of a modified antennal segmentation, is an autapomorphy of Megaloptera. Sensorial appendages occur on the penultimate segment in Raphidia (Fig. 10D; sen; Beutel \& Ge, 2008), in Neuroptera (e.g., Osmylus, Ithonidae, Polystoechotidae; Wundt, 1961; MacLeod, 1964; Grebennikov, 2004), and in beetle larvae (antennomere 3 in Cupedidae and Adephaga, penultimate antennomere 2 in Myxophaga and Polyphaga; e.g. Beutel, 1993, 1999; Beutel et al., 1998; Beutel \& Hörnschemeyer, $2002 \mathrm{~b}$ ). The presence of two appears to be the primary feature in Mecopterida (Lepidoptera, Rhyacophilidae, some basal groups of Diptera) (P. Švácha, pers. comm.). It is noteworthy that different forms of the antennal sensorial appendages occur in almost all orders of endopterygote insects, although its homologue is difficult to identify (but may be present) in hymenopteran larvae (P. Švácha, pers. comm.).

18. (1-4) Number of extrinsic antennal muscles: (0) 4; (1) 3; (2) 2; (3) 1; (4) absent. Three extrinsic antennal muscles are present in Corydalidae (Figs 6A, 9; Kramer, 1955), in most groups of Coleoptera (e.g., Beutel, 1993; Beutel \& Molenda, 1997; Beutel \& Hörnschemeyer, 2002b), and in Siphonaptera (Sharif, 1937). Four are present in Raphidia (Beutel \& Ge, 2008) and some groups of Neuroptera (e.g., Osmylus, Chrysopa, Coniopterygidae; Wundt, 1961; Rousset, 1966), Xyela (Beutel et al., 2008), and in larvae of some groups of Lepidoptera (Kristensen, 1984, 2003). Only two are preserved in Sialis (Röber, 1942) and Boreus (Beutel, pers. obs.) and only one in Myrmeleon (Korn, 1943) and some other lineages (e.g., Parker, 1935; Bierbrodt, 1942; Kramer, 1954). Total reduction occurs in groups with strongly or completely reduced antennae (Cook, 1949; Winkler, 1959; Kristensen, 1984; Pohl, 2000).

19. (o1-) Origin of extrinsic antennal muscles: (0) dorsal tentorial arms; (1) anterior tentorial arms; (2) anterior and dorsal arms; (3) anterior arm and suspensorium; (4) posterior arms; (5) ligament between anterior arm and gena; (6) head capsule. The antennal muscles originate from the dorsal tentorial arm in Corydalidae (Figs 6A, 9C, D; Kramer, 1955), Raphidia (Beutel \& Ge, 2008) and Chrysopa (Rousset, 1966), and this is also the case in Adephaga (Beutel, 1993) and basal hymenopteran lineages (Parker, 1935; Beutel et al., 2008). This is possibly the ancestral condition for Endopterygota. Two of four muscles arise from the anterior arm in Osmylus and two from the dorsal arms (Wundt, 1961). The poorly developed antennal muscles originate from the head capsule in Sialis (Röber, 1942) and this is also the case in beetle larvae with a reduced tentorium (Beutel \& Hörnschemeyer, 2002a, b; Beutel, 1995). An origin from the anterior arm occurs in Polyphaga (e.g., Beutel \& Molenda, 1997) and in antliophoran larvae (e.g., Bierbrodt, 1942; Widhalm-Finke, 1974; Kramer, 1954).

20. (iam) Intrinsic antennal muscles: (0) present; (1) absent. Intrinsic antennal muscles are absent in Corydalidae (Kramer, 1955) and in all other endopterygote larvae examined (e.g., Beutel \& Ge, 2008; Beutel et al.,
2008) with the possible exception of a species referred to as Chrysopa nobis by Rousset (1966: with ?).

21. (mol) Mola: (0) present; (1) absent or strongly reduced. A mandibular mola is generally absent in Neuropterida (e.g., Röber, 1942; Wundt, 1961; Rousset, 1966; Beutel \& Ge, 2008). It occurs in many groups of Coleoptera (Beutel \& Molenda, 1997; Beutel et al., 1998; Beutel \& Hörnschemeyer, 2002a, b) and in Panorpa (Bierbrodt, 1942), and in most groups of Lepidoptera (absent in Micropterix but present in Neomicropterix; Hasenfuss \& Kristensen, 2003).

22. (13) M. tentoriomandibularis: (0) present; (1) absent. A thin M. tentoriomandibularis is present in Neohermes (Fig. 9C), Raphidia (Beutel \& Ge, 2008) and Chrysopa (Rousset, 1966). The muscle is well developed in larvae of Osmylus (three subcomponents; Wundt, 1961), and is also present in basal hymenopteran groups (Beutel et al., 2008), in Nannochorista (Beutel, pers. obs.), and in larvae of basal groups of Lepidoptera (Kristensen, 1984, 2003). The muscle is not recorded for larvae or adults of many groups, but may have been overlooked in some cases due to its very small size.

23. (pmx) Position of maxilla: (0) retracted; (1) protracted, cardines at level of mentum; (2) protracted, cardines at level of prementum, maxillary groove absent. The maxillae of Corydalidae are in a less strongly retracted position (Figs 1B, 2B, 3C) compared to Sialis (Fig. 10B: mg), Osmylus, and Chrysopa (e.g., Crampton, 1921; Röber, 1942: Fig. 2; Wundt, 1961; Rousset, 1966), but a maxillary groove is still preserved like in larvae of Nevrorthidae and the myrmeleontiform lineage (MacLeod, 1964). The maxillary groove is completely absent and the maxillae in a fully protracted position in Raphidioptera (Fig. 10D; Aspöck et al., 1991: Figs 55, 63; Beutel \& Ge, 2008) and in some other groups (e.g., Panorpa, Siphonaptera, Adephaga excl. Gyrinidae; Bierbrodt, 1942; Widhalm-Finke, 1974; Beutel, 1993). The protracted maxilla of Raphidioptera is interpreted as plesiomorphic in Aspöck et al. (2001) and Aspöck \& Aspöck (2007).

24. (Ist) Length of stipes: (0) not distinctly elongated, less than $2 \times$ as long as wide; (1) more than $3 \times$ as long as wide. The stipes is slender and distinctly elongated in Corydalidae (Figs 1A: sti, 3C; Crampton, 1921; Kramer, 1955) compared to the condition found in Sialis. This is likely an autapomorphy of the family. The stipes is short in Sialis (Fig. 10B: sti) and also in Raphidia (Fig. 10D: sti; Beutel \& Ge, 2008) and presumably basal groups of Neuroptera [e.g., Osmylus, Nevrorthus, Chrysopa (sclérite stipital); Wundt, 1961; Zwick, 1967; Rousset, 1966]. In Aspöck et al. (2001) and Aspöck \& Aspöck (2007) it is hypothesised that the elongated stipes represents the maxillary component of the sucking tubes.

25. (col) Distal membranous collar of stipes: (0) absent; (1) present. The modification of the distal part of the stipes as a broad membranous collar (Fig. 3C, D: col) bearing the palp and galea is likely an autapomorphy of Corydalidae. 
26. (lac) Lacinia: (0) elongate hook-shaped structure along mesal stipital edge, with distinct, pointed apex and regular row of mesally directed spines and setae; (1) elongate, largely fused with stipes, with indistinct rounded apex and mesally directed setae; (2) hookshaped but shortened, with few mesally directed setae; (3) part of a specialised sucking apparatus; (4) vestigial or completely reduced. In contrast to Kramer (1955) and Neunzig \& Baker (1991) the lacinia is not absent in Corydalidae (Figs 3C, 4: 1c). It is represented by a narrow sclerotised lobe along the mesal side of the stipes, with mesally directed setae, and an indistinct, rounded apex. The hook-shaped inner lobe of Sialis was interpreted as a galea by Röber (1942), mainly based on the attachment of a muscle homologised with M. stipitogalealis. As both intrinsic muscles, M. stipitolacinialis (M. 20) and M. stipitogalealis (M. 21) are present in Neohermes, and the latter is very similar to M. 21 in Sialis, we follow the conventional view of Crampton (1921) and Das (1937), who designated the outer and inner lobe of Sialis as galea and lacinia, respectively. The larval lacinia of Megaloptera comes closest to the hook-shaped lacinia usually found in hemimetabolous insects. It is probably the main part of the maxillary element of the sucking jaws in Neuroptera (e.g., Wundt, 1961), even though a stipital origin of the sucking jaws was suggested by Aspöck et al. (2001) and Aspöck \& Aspöck (2007). The larval lacinia is distinctly reduced in Raphidioptera (Aspöck et al., 1991, Figs 58, 59, 66, 67; Beutel \& Ge, 2008) and other endopterygote lineages (Das, 1937; Beutel \& Hörnschemeyer, 2002a, b; Beutel, 1993, 1995, 1999; Parker, 1935; Wiggins, 1987; Kristensen, 2003; Pilgrim, 1972; Bierbrodt, 1942).

27. (cgp) Connection of galea and palp: (0) both elements inserted separately on the stipes; (1) palpifer and galea form a structural unit. In Corydalidae the galea is closely connected with the palpifer, which bears the 4-segmented palp (Fig. 3D; Crampton, 1921; Kramer, 1955). It is basally fused with the palpifer in Sialis (Fig. 10B; Crampton, 1921: Fig. 23; Röber, 1942: Fig. 8). A small peg-like galea inserted on the mesal side of the palpifer (or basal palpomere) occurs in larvae of few groups of Coleoptera (Beutel, 1993, 1999). The galea is not present as a separate element in Neuroptera (see previous character). Both maxillary elements are separately inserted on the stipes in most endopterygote lineages (e.g., Phaeostigma klimeschiella; Aspöck et al., 1991, Figs 58, 59, 66, 67; Beutel \& Ge, 2008).

28. (gal) Subdivision of galea: (0) not subdivided; (1) two segments; (2) three segments. The subdivision of a palp-like galea into three galeomeres (Fig. 3D) is likely an autapomorphy of Corydalidae. The galea is unsegmented in Sialis (Fig. 10B: ga; see previous character).

29. (nmp) Number of maxillary palpomeres: (0) five; (1) four; (2) three; (1) less than three. We consider the palp of Corydalidae as 4-segmented (Fig. 3D), a condition also found in Sialis (Röber, 1942). The palp of Raphidia (Fig. 10D: mxp) was described as 5-segmented in Beutel \& Ge (2008). However, it is conceivable that the very short basal element is a palpifer as it is likely the case in Corydalidae. It is also shown to be 4-segmented in Aspöck et al. (1991: Figs 58, 59, 66, 67). In Neohermes, the extrinsic palp muscles are attached to the segment following the structure interpreted as palpifer here. The palp is four segmented in the groundplan of Trichoptera and Mecoptera (e.g., Bierbrodt, 1942; 3-segmented in Nannochorista; Beutel, pers. obs.), and probably 3-segmented in the groundplan of Hymenoptera (Beutel et al., 2008), Lepidoptera (Hasenfuss \& Kristensen, 2003) and Coleoptera (Beutel \& Lawrence, 2005). It is two segmented in Strepsiptera (Pohl, 2000), Boreus (Beutel, pers. obs.), Siphonaptera (Widhalm-Finke, 1974) and in the groundplan of Diptera (Hennig, 1973). The palp is reduced in Neuroptera (e.g., Wundt, 1961).

30. (mpx) Size of maxillary palp: (0) longer than stipes: (1) greatly reduced in length. The maxillary palp of Neohermes (Fig. 3D) and other members of Corydalidae is strongly shortened (Crampton, 1921; Neunzig \& Baker, 1991). This is a potential autapomorphy of the family. The complete loss is an autapomorphy of Neuroptera (e.g., MacLeod, 1964).

31. (omm) Orientation of extrinsic tentoriomaxillary muscles: (0) oblique or nearly vertical; (1) longitudinal. The oblique or almost vertical arrangement of the extrinsic tentorio-maxillary muscles in Megaloptera (Fig. 6B; Kramer, 1955; Röber, 1942: Fig. 10) and Neuroptera (Korn, 1943: Figs 4, 5; Wundt, 1961: Fig. 9) is almost certainly a plesiomorphic condition compared to the longitudinal arrangement of $\mathrm{M}$. craniocardinalis, M. tentoriocardinalis, M. tentoriostipitalis and M. craniolacinialis in larvae of Raphidia (Beutel \& Ge, 2008) and some other groups (e.g., Adephaga; Beutel, 1993).

32. (15) M. craniocardinalis: (0) present; (1) absent. The presence in Megaloptera (Fig. 6B; Kramer, 1955; Röber, 1942: Fig. 10) is clearly plesiomorphic. M. 15 is also present in Raphidia (Beutel \& Ge, 2008), and in Coleoptera (with few exceptions; e.g., Das, 1937; Beutel, 1993, 1995, 1999). It is absent in Osmylus (Wundt, 1961) and other members of Neuroptera (Rousset, 1966), in Amphiesmenoptera (Das, 1937; Hasenfuss \& Kristensen, 2003), in Mecoptera (Bierbrodt, 1942; Beutel, pers. obs.), and in Diptera (Das, 1937; Cook, 1949). Whether the muscle considered as abductor of the cardo in Siphonaptera by Sharif (1937) and Widhalm-Finke (1974: Abductor maxillae II) is indeed homologous with M. craniocardinalis is uncertain. The dorsal insertion is atypical and the basal part of the maxilla may not be homologous with the cardo (Matsuda, 1965).

33. (17) Subdivision of M. tentoriocardinalis: (0) absent, muscle undivided; (1) present, two subcomponents. The subdivision of the muscle into two distinct subunits (Figs 6B, 7B; Kramer, 1955) is a potential autapomorphy of Corydalidae. A single bundle is present in Sialis (Röber, 1942).

34. (18) Subdivision of M. tentoriostipitalis: (0) absent, muscle undivided; (1) present, two subcomponents. Like M. 17, M. 18 is also subdivided into two separate subunits in Corydalidae (Figs 6B, 7B; Kramer, 
1955). This is also a potential autapomorphy of the family.

35. (20) M. stipitolacinialis: (0) absent; (1) present. The presence of M. 20 in Neohermes is apparently a plesiomorphic feature. It is conceivable that the unconspicuous intrinsic muscle of the maxilla was overlooked by Kramer (1955). The muscle occurs in the other neuropterid lineages (Röber, 1942; Wundt, 1961; Beutel \& Ge, 2008) and in Coleoptera and Hymenoptera (Beutel et al., 2008). It is absent in Antliophora (e.g., Bierbrodt, 1942; Cook, 1949; Widhalm-Finke, 1974; Sharif, 1937), Strepsiptera (Pohl, 2000), and probably also in Lepidoptera (Hasenfuss \& Kristensen, 2003) and Trichoptera (Fotius-Jaboulet, 1961). The muscle interpreted as M. 20 by Winkler (1959) is likely one of the palp muscles (N. Kristensen, pers. comm.).

36. (asl) Notched anterolateral submental lobes: (0) absent; (1) present. The submentum of Corydalidae is excavated anteromedially and the anterolateral lobes are characterised by a sharply defined notch (Figs 1B, 2B, $3 \mathrm{C}$ ), which probably serves as a resting device for the maxilla (Fig. 2B). This condition is likely an autapomorphy of Corydalidae.

37. (men) Mentum: (0) well developed, separated from submentum; (1) strongly reduced, membranous; (2) fused with the submentum; (3) postlabium absent. The mentum is well developed and distinctly separated from the submentum in Megaloptera (Figs 1B, 2B, 10B; Crampton, 1921; Röber, 1942; Kramer, 1955), Nevrorthus, in larvae of many groups of Coleoptera (e.g., Beutel \& Molenda, 1997), in Trichoptera (Wiggins, 1987), and in symphytan larvae (Parker, 1935). The mentum is membranous and attached to the anteroventral margin of the head capsule in Raphidioptera (Phaeostigma, Parainocellia; Aspöck \& Aspöck, 2007; Aspöck et al., 1991, Fig. 69; Beutel \& Ge, 2008) like in some groups of Coleoptera (e.g., Adephaga, Histeridae; Beutel, 1993, 1999) and in larvae of Panorpa and Apterobittacus (Bierbrodt, 1942; Applegarth, 1939). The mentum is fused with the submentum in Neuroptera (excl. Nevrorthidae; e.g., Wundt, 1961; Grebennikov, 2004), Lepidoptera (Kristensen, 2003), and in Siphonaptera (Sharif, 1937; Widhalm-Finke, 1974).

38. (glp) Glossa and paraglossa: (0) present; (1) absent. The glossa and paraglossae are not developed as recognisable separate structures in Megaloptera (Fig. 3C; Röber, 1942; Kramer, 1955) and other endopterygote lineages and the associated premental muscles are also missing (e.g., Crampton, 1921; Parker, 1935; Winkler, 1959; Cook, 1949; Beutel, 1993, 1995, 1999). The ligula (see following character) may represent modified or vestigial glossae and paraglossae.

39. (lig) Ligula: (0) absent; (1) single lobe; (2) bilobed. The ligula is bilobed in Corydalidae (Fig. 3C; Crampton, 1921; Kramer, 1955) whereas a single convex lobe is present in Sialis (Fig. 10B; Röber, 1942) and Raphidia (Fig. 10D; Crampton, 1921; Beutel \& Ge, 2008). It is also undivided in most beetle larvae where it is present (e.g., Beutel, 1993, 1999). A membranous ligula is absent in several groups of Endopterygota such as Antliophora and Mecoptera.

40. (lps) Number of segments of labial palp: (0) three; (1) two; (2) one. The palp is three-segmented in Megaloptera (Figs 1B, 2B, 3C; Crampton, 1921; Röber, 1942; Kramer, 1955), Raphidioptera (Fig. 10D; Aspöck et al., 1991, Fig. 60; Beutel \& Ge, 2008), and in symphytan larvae (e.g., Xyelidae, Tenthredinidae; Parker, 1935; Smith \& Middlekauff, 1991; Beutel et al., 2008). This is likely a groundplan feature of Endopterygota. More than three segments are present in several groups of Neuroptera (Zwick, 1967; New, 1991). Two are present in Coleoptera (with few exceptions; Beutel \& Hörnschemeyer, 2002b; Beutel, 1993, 1995, 1999), Trichoptera (partim; Hinton, 1958; Wiggins, 1987), Lepidoptera (Kristensen, 2003) and Mecoptera (partim; Byers, 1987). Only one palpomere is present in some groups of Coleoptera (e.g., Micromalthidae; Beutel \& Hörnschemeyer, 2002a), in some groups of Trichoptera (Hinton, 1958), in Caurinus (Boreidae; Russell, 1982), in Siphonaptera (Sharif, 1937; Widhalm-Finke, 1974), and in some nematoceran larvae (Kramer, 1954; Foote, 1991). Labial palps are absent in larvae of Strepsiptera (Pohl, 2000) and in larvae of many nematoceran groups.

41. (phl) Prementohypopharyngeal lobe: (0) absent; (1) present. A prementohypopharyngeal lobe as it is present in symphytan larvae (Parker, 1935; Beutel et al., 2008) and in Glossata (Hasenfuss \& Kristensen, 2003). It is absent in Neuropterida and the other groups of Endopterygota (e.g., Röber, 1942; Kramer, 1955; MacLeod, 1964; Rousset, 1966).

42. (28) M. submentopraementalis: (0) present; (1) absent. The muscle is present in Megaloptera (Figs 8, 9B-E; Röber, 1942; Kramer, 1955), in Raphidia (Das, 1937; Beutel \& Ge, 2008), and in Osmylus (Wundt, 1961; absent in Myrmeleon; Korn, 1943). It is also present in the groundplan of Coleoptera (e.g., Beutel, 1993, 1995, 1999) and in most symphytan larvae (Beutel et al., 2008; Parker, 1935: absent in Tenthredinidae). It is absent in Archostemata (Beutel \& Hörnschemeyer, 2002a, b) and some other groups of Coleoptera (Beutel, 1993), and also in primary larvae of Strepsiptera (Pohl, 2000). It is usually also missing in Mecopterida (e.g., Winkler, 1959; Kristensen, 2003; Bierbrodt, 1942; Cook, 1949), possibly present in Siphonaptera (Sharif, 1937; Wilhalm-Finke, 1974).

43. (31) M. praementoparaglossalis: (0) present; (1) absent. The muscles are absent in Megaloptera (Röber, 1942; Kramer, 1955) and all other endopterygote larvae (e.g., Wundt, 1961; Rousset, 1966; Beutel \& Ge, 2008; Das, 1937).

44. (32) M. praementoglossalis: (0) present; (1) absent. Also absent in all endopterygote larvae (e.g., Röber, 1942; Beutel \& Ge, 2008; Korn, 1943; Wundt, 1961; Rousset, 1966; Parker, 1935; Das, 1937).

45. (34) M. praementopalpalis externus: (0) present; (1) absent. M. praementopalpalis externus is present in Megaloptera and the other neuropterid lineages (Das, 1937; Röber, 1942; Wundt, 1961; Beutel \& Ge, 2008) 
and also in basal hymenopteran groups (Beutel et al., 2008; Parker, 1935) and in the groundplan of Coleoptera (e.g., Das, 1937; Beutel, 1993, 1995). It is absent in Mecopterida (Das, 1937; Winkler, 1959; Kristensen, 2003; Cook, 1949; Kramer, 1954) and is also missing in Archostemata (Beutel \& Hörnschemeyer 2002a, b) and Strepsiptera (Pohl, 2000).

46. (tlm) Transverse labial muscle. (0) absent; (1) present. A transverse labial muscle is present in Sialis (Röber, 1942), but absent in Corydalidae (Kramer, 1955) and most other groups of endopterygote insects. It occurs in some groups of Coleoptera (Beutel \& Hörnschemeyer, 2002a; Beutel \& Friedrich, 2005) and in Xyela, Janus and Xiphydria (Beutel et al., 2008).

47. (42) M. tentoriohypopharyngalis: (0) present; (1) absent. M. 42 is present in Neohermes (Figs 8, 9B-E) and Corydalus (interpreted as labial muscle by Kramer, 1955), and probably also in Sialis (interpreted as part of a premental retractor by Röber, 1942) and Neuroptera (Wundt, 1961: M. 21 [M. tentoriohypopharyngalis]; Rousset, 1966: dvc). It is also present in Trichoptera (Hasenfuss \& Kristensen, 2003) and Nannochorista, and probably also in basal Hymenoptera, but with the origin shifted to the posterior head capsule (Beutel et al., 2008: prelabio-hypopharyngeal muscle). M. 42 is absent in Siphonaptera (Sharif, 1937), and probably also in Panorpa (Bierbrodt, 1942) and Diptera (e.g., Kramer, 1954; Cook, 1949). However, the identity of the single muscle assigned to the labium in these groups is disputable. M. 42 is generally absent in Coleoptera and Strepsiptera. The muscle interpreted as M. tentoriohypopharyngalis in studies on the larval head morphology (e.g., Beutel 1993, 1999; Beutel \& Ge, 2008) functions as a hypopharyngeal retractor and originates on the tentorium, but is in fact homologous with v. Kéler's M. tentoriobuccalis anterior (M. 48; v. Kéler, 1963).

48. (49) M. tentoriobuccalis lateralis: (0) absent; (1) present. A lateral tentoriopharyngeal dilator originating on the upper part of the dorsal tentorial arm is present in Corydalidae (Kramer, 1955: dphd ${ }_{3}$ ) but absent in other groups of Endopterygota. This is a potential autapomorphy of the family.

49. (51) M. verticopharyngalis: (0) one bundle; (1) several distinctly separated subcomponents; (2) absent. M. verticopharyngalis is composed of several distinctly separated subunits in Megaloptera (Figs 8, 9F; Röber, 1942. Fig. 12; Kramer, 1955). Two subunits are present in Boreus, Xyela (Beutel et al., 2008), Tenthredinidae (Parker, 1935), and Siphonaptera (strongly developed; Sharif, 1937), and three in Nannochorista and Panorpa (Bierbrodt, 1942). The muscle is not divided into clearly separated subcomponents in Raphidia (Beutel $\&$ Ge, 2008: one thin bundle), Myrmeleon (Korn, 1943), Osmylus (Wundt, 1961: fig. 20 [one of four bundles slightly shifted laterad]), Trichoptera (Winkler, 1959; Fotius-Jaboulet, 1961; Beutel, pers. obs.), Bittacomorpha (Kramer, 1954) and Bibio (insertions slightly separated; Beutel, pers. obs.). The muscle is usually weakly developed or absent in beetle larvae (e.g., Beutel, 1993, 1995,
1999) and also missing in Strepsiptera (Pohl, 2000) and in the groundplan of Lepidoptera (Kristensen, 1984, 2003).

50. (52) M. tentoriopharyngalis: (0) one or two closely adjacent bundles or a series arranged as one unit; (1) two or three distinctly separated subcomponents; (2) absent. M. 52 is composed of two distinctly separated subcomponents in Corydalidae (Fig. 8; Kramer, 1955) and a similar condition is present in Nannochorista. Several thin bundles forming one unit are present in Sialis (Röber, 1942: M. postgeno-pharyngealis, Fig. 12), Osmylus (Wundt 1961: Fig. 20) and Chrysopa (Rousset, 1966: Figs 66, 69), and two parallel bundles in Raphidia (Beutel \& Ge, 2008). Two closely adjacent bundles are also present in Agathiphaga (Kristensen, 1984), two thin parallel bundles in Rhyacophila (Beutel, pers. obs.), and several bundles forming one unit in Mecoptera (Bierbrodt, 1942; excluding Nannochorista), in basal Hymenoptera (Parker, 1935; Beutel et al., 2008), in Bittacomorpha (Kramer, 1954), and in Siphonaptera (Sharif, 1937). M. 52 is probably absent in most groups of Diptera (Cook, 1949) and in primary larvae of Strepsiptera (Pohl, 2000). It is usually small or absent in beetle larvae (e.g., Beutel 1993, 1995, 1999), but one or two series of bundles are present in few groups (Beutel, 1993: Haliplidae, Dytiscoidea; Beutel \& Hörnschemeyer, 2002b: Cupedidae).

51. (ctp) Craniotentorial muscle muscle (Kramer, 1955: ctph): (0) absent; (1) present. A thin muscle running from the vertex laterad of the pharynx to the posterior tentorial arm was described for Corydalus by Kramer (1955). This muscle is absent in Neohermes and is also unknown in other groups of insects (e.g., Röber, 1942; Wundt, 1961; Rousset, 1966; Beutel \& Ge, 2008). It is conceivable that this muscle does only occur in larvae of larger corydalid species.

52. (sal) Proximal salivary duct: (0) well developed; (1) strongly narrowed, without recognisable lumen; (2) absent. A narrow, vestigial proximal salivary tube is present in Neohermes (Figs 8, 9A) and also in Sialis (not described by Röber [1942]). It is well developed in Raphidia (Beutel \& Ge, 2008) and Neuroptera (Wundt, 1961; MacLeod, 1964; Rousset, 1966), and also in most other groups of endopterygote insects (e.g., Parker, 1935; Winkler, 1959; Kristensen, 1984; Cook, 1949). It is absent in Coleoptera (Beutel \& Hörnschemeyer, 2002a, b; Beutel, 1993, 1995, 1999; Beutel \& Molenda, 1997) and Strepsiptera (Pohl, 2000).

53. (37) M. hypopharyngosalivarialis: (0) present; (1) absent. The muscle is well developed in Corydalidae (Fig. 9A; Kramer, 1955) and most other groups of Endopterygota. It is probably represented by M. dorsoventralis labialis in Sialis (Röber, 1942) (coded as 0). It is absent in Raphidia, in Xyela and some other basal representatives of Hymenoptera (present in Janus; Beutel et al., 2008), in Coleoptera (e.g., Beutel, 1993, 1995, 1999), and in Strepsiptera (H. Pohl, pers. comm.).

54. (38/39) Mm. praementosalivariales anterior and posterior: (0) present; (1) absent. Both muscles are well developed in Corydalidae (Figs 8, 9A; Kramer, 1955). 
One is present in Raphidia (Beutel \& Ge, 2008), Osmylus (Wundt, 1961), Micropterix (Hasenfuss \& Kristensen, 2003), and in some basal groups of Hymenoptera (e.g., Neodiprion, Dolerus, absent in Xyela and Janus; Beutel et al., 2008). They are absent in most groups of Endopterygota.

55. (nco) Nervus connectivus: (0) present; (1) absent. The nervus connectivus is present in Neohermes (Fig. 5), Raphidia (Beutel \& Ge, 2008), in some neuropteran larvae (Osmylus, Chrysopa; Rousset, 1966), and also in Panorpa (Bierbrodt, 1942). The presence is likely a groundplan feature of Endopterygota. The nerve is absent in Nannochorista, Xyela, Limnephilus (Fotius-Jaboulet, 1961), Agathiphaga (Kristensen, 1984), Coleoptera (e.g., Jösting, 1942; Beutel, pers. obs.), Strepsiptera (Beutel et al., 2005), and Nosopsyllus (Sharif, 1937).

\section{DISCUSSION}

Larvae of Corydalidae and Sialidae are mainly characterised by plesiomorphic features such as distinct frontal and coronal sutures, the presence of six stemmata, a movable labrum with a full set of extrinsic and intrinsic muscles, a thin but recognisable tentoriomandibular muscle, the presence of a maxillary groove, 4-segmented maxillary palps, the oblique or nearly vertical arrangement of the extrinsic maxillary muscles, a labium with all components except for the glossae and paraglossae, 3-segmented labial palps, and a largely complete muscle system. The presence of a nervus connectivus is also likely plesiomorphic. However, this feature needs more study in other groups.

Character states identified as potential larval autapomorphies of Endopterygota in earlier studies (e.g., Beutel $\&$ Ge, 2008; Beutel et al., 2008) are confirmed for Corydalidae. These features include the absence of intrinsic antennal muscles, the reduction of glossae and paraglossae, and the absence of M. praementoglossalis and M. praementoparaglossalis. A supposedly derived feature found in larvae of Neuropterida (Figs 1, 10) and larvae of almost all other groups of endopterygote insects is the presence of one or two sensorial appendages on the antepenultimate or penultimate antennomere, although homology is difficult to establish in larvae of Hymenoptera (P. Švácha, pers. comm.).

Few features investigated here support the monophyly of Neuropterida. Prognathism and the absence of a mandibular mola are potential autapomorphies of this lineage. However, the polarity of both characters is ambiguous as a prognathous head and mandibles without molae do also occur in other endopterygote groups (e.g., Nannochoristidae, Siphonaptera, Diptera; e.g., Pilgrim, 1972; Sharif, 1937; Cook, 1949). Besides this, the head of Sialis is subprognathous. Whether this is plesiomorphic or due to reversal is presently unclear. The monophyly of Megaloptera, which was often challenged (e.g., Achtelig, 1967; Büning, 1998), is supported by three presumably apomorphic character states of the larval head, the insertion of a peg-like or spine-shaped sensillum on the antepenultimate antennomere, the vestigial condition of the salivary duct, and a verticopharyngeal muscle composed of several subcomponents. The latter features also occur in other groups. The salivary duct is generally absent in beetle larvae and M. verticopharyngalis is also composed of three separate bundles in Nannochorista and Panorpa (Bierbrodt, 1942). The monophyly of Megaloptera is further corroborated by molecular analysis (Haring \& Aspöck, 2004) and by a hitherto overlooked derived groundplan feature; the presence of eversible sacs within the complex of the fused gonocoxites 11 in Corydalidae and Sialidae (Aspöck \& Aspöck, 2008).

Despite the overall similarity of megalopteran larvae, they differ in a considerable number of features of the head. Corydalus is plesiomorphic compared to Sialidae in several characters. The reduction of parts of the tentorium, the reduced condition of the antennal muscles, the presence of a transverse labial muscle, and the loss of muscles of the salivary duct are likely autapomorphies of Sialidae. It has to be stated in this context, that in contrast to Röber (1942), anterior tentorial arms are present in Sialis even though very thin (N. Kristensen, pers. comm.). Whether the presence of a sclerotised gular plate is plesiomorphic or apomorphic is unclear. The character state distribution is similar as in the case of the neck region (see below). It is conceivable that the absence in Sialis and several groups of Neuroptera (e.g., Osmylidae, Coniopterygidae, Chrysopidae; Rousset, 1966; Aspöck et al., 2001; Aspöck \& Aspöck, 2007) is due to reversal.

The monophyly of Corydalidae is strongly supported by features of the larval head, especially by characters related to the maxilla. Presumptive autapomorphies are the distinctly reduced maxillary groove, the strongly elongated stipes, the distal membranous stipital collar, the distinctly reduced lacinia, the close connection between palp and galea, the subdivision of the galea, the shortened palp, and the bipartite M. tentoriocardinalis and M. tentoriostipitalis. Additional autapomorphies are the postgular plate and the anterolateral submental notch. Derived conditions only found in some members of the family, especially in large species, are the 5-segmented antenna and the presence of a craniotentorial muscle described by Kramer (1955). The monophyly of the subfamilies Corydalinae and Chauliodinae is not supported by features of the larval head.

A closer phylogenetic affinity between Corydalidae and Raphidioptera was suggested by Achtelig (1967) based on characters of adults. A shared feature of larvae is the presence of a parietal ridge (Beutel \& Ge, 2008). However, a similar structure does also occur in Coleoptera (Beutel, 1993), and the ridge may be secondarily absent in Sialis. Another presumably derived feature found in both groups is the anterior position of the posterior tentorial grooves. This condition has independently evolved in many groups of Coleoptera with predacious larvae (Beutel, 1993, 1999; Beutel \& Molenda, 1997), and is also present in Nevrorthidae, Myrmeleontiformia and Siphonaptera (Sharif, 1937). A distinct neck region is another feature shared by Corydalidae and Raphidioptera. As it is also present in Nevrorthidae and Myrmeleontiformia 
("head-cervix-articulation" in Aspöck, 1992: Fig. 7), it is conceivable that this is a derived groundplan feature of Neuropterida. A neck region occurs in few groups of Coleoptera (e.g., Gyrinidae [partim]; Beutel, 1993), but is almost certainly absent in the groundplan of the order (Beutel \& Hörnschemeyer, 2002a, b; Beutel et al., 1998; Beutel \& Molenda, 1997).

A closer relationship between Sialidae and Raphidioptera, based on the presence of specific telotrophic ovarioles, as suggested by Štys \& Biliński (1990) and Kubrakiewicz (1998), is not supported by the results of our study. This hypothesis is also in contrast to Büning (1998), who pointed out specific conditions of the somatic ovarian tissues shared by Corydalidae and Sialidae. This suggests that the panoistic ovarioles of Corydalidae may be a secondary feature. As already pointed out by Beutel \& Ge (2008), in this case the specialised telotrophic condition would be a strong argument for a clade comprising Raphidioptera and a monophylum Megaloptera (see also Kristensen, 1999). This more inclusive lineage was also suggested by Achtelig \& Kristensen (1973) and Achtelig (1978) based on the presence of a gula in adults and the cleaning behaviour, and by Beutel \& Gorb (2006) based on the presence of hairy tarsal attachment devices with a specific type of tenent setae. A potential synapomorphy of the larval head is the presence of a circular ridge anterad of the neck region (Figs 1, 10A, C: cri). The increased number of eight Semper cells and 20-45 retinula cells in the stemmata (Paulus, 1986) are further potential synapomorphies of the two orders. A clade comprising Raphidioptera and Megaloptera was also suggested in a molecular study based on $18 \mathrm{~S}$ rDNA of 182 endopterygote terminal taxa (Whiting, 2002). However, as already pointed out by Beutel \& Ge (2008), Sialis was the only megalopteran representative included and the bootstrap value for the clade is low (61). Megaloptera turned out as paraphyletic in another analysis of 18S rDNA sequence data (Winterton, 2003), and Raphidioptera as the sistergroup of Neuroptera.

A megalopteran-raphidiopteran clade is in contrast to a sistergroup relationship between Megaloptera and Neuroptera, which was proposed by Aspöck (1995, 2002) based on several potential synapomorphies such as a specific rosette-like arrangement of trichobothria on the ectoproct, primarily aquatic habits of larvae, the elongation of the larval stipites, and the "integration of the larval cardines in the head capsule" (Aspöck et al., 2001; Aspöck, 2002: p. 52). Megaloptera + Neuroptera were also corroborated by a molecular analysis (Haring \& Aspöck, 2004) and by Aspöck \& Aspöck (2008). As already pointed by Beutel \& Ge (2008), the stipes is not elongated in Sialis and the retracted position of the maxillae, i.e. the presence of a distinct fossa maxillaris, is likely a plesiomorphic feature. Apparently, analyses of an extensive combined data set will be required for the solution of this crucial controversy in the systematics of Neuropterida.

ACKNOWLEDGEMENTS. The gift of specimens of Neohermes by D. Maddison (University of Arizona) and of many unidentified corydalid larvae from Nepal by O. Moog (Universität für Bodenkunde, Wien) is gratefully acknowledged. We are also grateful to A. Staniczek (Staatliches Museum für Naturkunde Stuttgart) for arranging the loan of larval specimens of Archichauliodes. We also thank E. Altenhofer (Groß-Gerungs, Österreich), D.C. Carlton (Louisiana State University), T. Galloway (University of Manitoba), B. Krasnov (Ben Gurion University of Negev) and M. Whiting (Brigham Young University, Provo, Utah) for the gift of valuable material. U. Aspöck and F. Anderle (Naturhistorisches Museum Wien) provided valuable literature. This is also gratefully acknowledged. We are also grateful for many valuable suggestions made by the reviewers, U. Aspöck and N.P. Kristensen (ZMUC, Copenhagen). They helped greatly to improve this study. The project was supported by the German Science Foundation (DFG) which is also gratefully acknowledged (BE 17989/4-1).

\section{REFERENCES}

Achtelig M. 1967: Über die Anatomie des Kopfes von Raphidia flavipes Stein und die Verwandtschaftsbeziehungen der Raphidiidae zu den Megalopteren. Zool. Jb. Anat. Ontog. Tiere 84: 249-312.

Achtelig M. 1978: Entwicklung und Morphologie der inneren und äußeren weiblichen Genitalorgane der Kamelhalsfliegen (Neuropteroidea: Raphidioptera). Entomol. Germ. 4: 140-163.

Achtelig M. \& KRISTENSEN N.P. 1973: A re-examination of the relationships of the Raphidioptera (Insecta). Z. Zool. Syst. Evolut.-Forsch. 11: 268-274.

Anthon H. 1943: Zum Kopfbau der primitivsten bisher bekannten Dipterenlarve: Olbiogaster sp. (Rhyphidae). Ein Beitrag zur Phylogenie der nematoceren Dipteren. Entomol. Medd. 23: 302-320.

Applegarth A.G. 1939: The larva of Apterobittacus apterus Maclachlan (Mecoptera: Panorpidae) Microentomology 4: 109-120.

AsPöcK U. 1992: Crucial points in the phylogeny of the Neuroptera (Insecta). In Canard M., Aspöck H. \& Mansell M.W. (eds): Current Research in Neuropterology. Proceedings of the Fourth International Symposium on Neuropterology. Bagnères-de-Luchon, France, 1991. pp. 63-73.

AsPöcK U. 1995: Neue Hypothesen zum System der Neuropterida. Mitt. Dt. Ges. Allg. Angew. Entomol. 46: 633-636.

AsPöck U. 2002: Phylogeny of the Neuropterida (Insecta: Holometabola). Zool. Scr. 31: 51-55.

AsPöcK H. \& AspöcK U. 1971: Raphidioptera (Kamelhalsfliegen). Handb. Zool. IV, Insecta. Inst. 15. Walter de Gruyter, Berlin, 48 pp.

AsPöck U. \& AsPöcK H. 2005: Neuropterida (Neuropteroidea, Neuroptera sensu lato). In Dathe H.H. (ed.): Lehrbuch der Speziellen Zoologie, begründet von A. Kaestner, Band I, 5. Teil: Insecta. 2nd ed. Spektrum Akademischer Verlag, Heidelberg, Berlin, pp. 542-584.

AsPöck U. \& AsPÖCK H. 2007: Verbliebene Vielfalt vergangener Blüte. Zur Evolution, Phylogenie und Biodiversität der Neuropterida (Insecta: Endopterygota). Denisia 20, NS 66: 451-516.

AsPöcK U. \& AsPÖCK H. 2008: Phylogenetic relevance of the genital sclerites of Neuropterida (Insecta: Holometabola). Syst. Entomol. 33: 97-127.

Aspöck H., Aspöck U. \& Rausch H. 1991: Die Raphidiopteren der Erde. Eine monographische Darstellung der Systematik, Taxonomie, Biologie, Ökologie und Chorologie der rezenten Raphidiopteren der Erde, mit einer zusammenfassenden Übersicht der fossilen Raphidiopteren (Insecta: Neuropteroidea). Goecke \& Evers, Krefeld, 2 Vols, 730 \& 550 pp. 
Aspöck U., Plant J.D. \& NemeschKal H.L. 2001: Cladistic analysis of Neuroptera and their systematic position within Neuropterida (Insecta: Holometabola: Neuropterida: Neuroptera). Syst. Entomol. 26: 73-86.

Beutel R.G. 1993: Phylogenetic analysis of Adephaga (Coleoptera) based on characters of the larval head. Syst. Entomol. 18: $127-147$.

BeUtel R.G. 1995: Phylogenetic analysis of Elateriformia (Coleoptera: Polyphaga) based on larval characters. J. Zool. Syst. Evol. Res. 33: 145-171.

Beutel R.G. 1999: Morphology and evolution of the larval head structures of Hydrophiloidea and Histeroidea (Coleoptera: Staphylinidae). Tijdschr. Entomol. 142: 9-30.

Beutel R.G. \& Friedrich F. 2005: Comparative study of larvae of Tenebrionoidea (Cucujiformia, Coleoptera). Eur. J. Entomol. 102: 241-264.

Beutel R.G. \& Ge S.-Q. 2008: The larval head of Raphidia (Raphidioptera, Insecta) and its phylogenetic significance. Zoology (Jena) 111: 89-113.

Beutel R.G. \& Gorb S. 2006: A revised interpretation of the evolution of attachment structures in Hexapoda (Arthropoda), with special emphasis on Mantophasmatodea. Arthrop. Syst. Phyl. 64: 3-25.

Beutel R.G. \& Hörnschemeyer T. 2002a: Larval morphology and phylogenetic position of Micromalthus debilis LeConte (Coleoptera: Micromalthidae). Syst. Entomol. 27: 169-190.

Beutel R.G. \& Hörnschemeyer T. 2002b: Description of the larva of Rhipsideigma raffrayi (Coleoptera, Archostemata), with phylogenetic and functional implications. Eur. J. Entomol. 99: 53-66.

Beutel R.G. \& Lawrence J.F. 2005: 4. Coleoptera, Morphology. In Beutel R.G. \& Leschen R.A.B. (volume eds): Coleoptera, Vol. I. Morphology and Systematics (Archostemata, Adephaga, Myxophaga, Polyphaga partim). Handbook of Zoology Vol. IV, Arthropoda: Insecta. Part 38. De Gruyter, Berlin, New York, pp. 23-27.

Beutel R.G. \& Molenda R. 1997: Comparative morphological study of larvae of Staphylinoidea (Coleoptera, Polyphaga) with phylogenetic implications. Zool. Anz. 236: 37-67.

Beutel R.G. \& PoHL H. 2006: Endopterygote systematics where do we stand and what is the goal (Hexapoda, Arthropoda). Syst. Entomol. 31: 202-219.

Beutel R.G., Maddison D.R. \& HaAs A. 1998: Phylogenetic analysis of Myxophaga (Coleoptera) using larval characters. Syst. Entomol. 24: 1-23.

Beutel R.G., Pohl H. \& HÜNefeld F. 2005: Strepsipteran brains and effects of miniaturisation. Arthrop. Struct. Dev. 34: 301-313.

Beutel R.G., Vilhelmsen L. \& Krogmann L. 2008: The larval head morphology of Xyela sp. (Xyelidae, Hymenoptera) and its phylogenetic implications. J. Zool. Syst. Evol. Res. 46: 118-132.

Bierbrodt E. 1942: Der Larvenkopf von Panorpa communis L. und seine Verwandlung, mit besonderer Berücksichtigung des Gehirns und der Augen. Zool. Jb. Anat. 68: 49-136.

Byers G.W. 1987: Mecoptera (Scorpion-flies, hanging flies). In Stehr F.W. (ed.): Immature Insects, Vol. I. Kendall/Hunt Publishing Company, Dubuque, Iowa, pp. 246-252.

BüNING J. 1998: The ovariole structure, type, and phylogeny. Microsc. Anat. Invert. (C) 11: 897-932.

Cook E.F. 1949: The evolution of the head in the larvae of Diptera. Microentomology 14: 1-57.

Crampton G.C. 1921: The sclerites of the head and the mouthparts of certain immature and adult insects. Ann. Entomol. Soc. Am. 14: $65-103+$ pls.
CzıнAк G. 1953: Beiträge zur Anatomie des Thorax von Sialis flavilatera L. Österr. Zool. Z. 4: 421-448.

DAS G.M. 1937: The musculature of the mouth-parts of insect larvae. Quart. J. Microsc. Sci. 80: 39-80.

DAvis D.R. 1987: Suborder Zeugloptera, Micropterigidae (Micropterigoidea). Suborder Dacnonypha, Eriocraniidae (Eriocranioidea). In Stehr F.W. (ed.): Immature Insects. Vol. I. Kendall/Hunt Publishing Company, Dubuque, Iowa, pp. 341-346.

Foote B.A. 1991: Tanyderidae (Tanyderoidea) - Chironomidae (Chironomoidea). In Stehr F.W. (ed.): Immature Insects. Vol. II. Kendall/Hunt Publishing Company, Dubuque, Iowa, pp. $730-762$.

Fotius-Jaboulet M.-C. 1961: Squelette et musculature céphaliques de la larve de Drusus trifidus Mac Lachlan (Trichoptera - Limnophilidae). Trav. Lab. Zool. Stat. Aquic. Grimaldi Fac. Sci. Dijon 31: 1-17 + figs.

GLoRioso M.J. 1981: Systematics of the dobsonfly subfamily Corydalinae (Megaloptera: Corydalidae). Syst. Entomol. 6: 253-290.

GrebenNiKov V.V. 2004: Grub-like larvae of Neuroptera (Insecta): a morphological review of the families Ithonidae and Polystoechotidae and a description of Oliarces clara. Eur. J. Entomol. 101: 409-417.

Grimaldi D. \& Engel M.S. 2005: Evolution of the Insects. Cambridge University Press, Cambridge, UK, 755 pp.

Haring E. \& AsPöck U. 2004: Phylogeny of the Neuropterida: a first molecular approach. Syst. Entomol. 29: 415-430.

HASENFuss I. \& KRISTENSEN N.P. 2003: Skeleton and muscles: immatures. In Kristensen N.P. (ed.): Lepidoptera, Moths and Butterflies. Vol. 2: Morphology, Physiology, and Development. Handbook of Zoology. Vol. IV. Arthropoda: Insecta. Part 36. Walter de Gruyter, Berlin, New York, pp. 133-164.

Hennig W. 1973: Diptera (Zweiflügler). Handbuch der Zoologie IV. Insecta. Inst. 20. de Gruyter, Berlin 337 pp.

Hinton H.E. 1958: The phylogeny of the panorpoid orders. Annu. Rev. Entomol. 3: 118-206.

Jösting E.A. 1942: Die Innervierung des Skelettmuskelsystems des Mehlwurms (Tenebrio molitor L., Larve). Zool. Jb. Anat. 67: $381-460$.

KÉLER S. v. 1963: Entomologisches Wörterbuch. Akademie Verlag, Berlin, $774 \mathrm{pp}$

KeLSEY L.P. 1954: The skeleto-motor mechanism of the dobson fly, Corydalus cornutus. Part I. Head and prothorax. Cornell Univ. Mem. 334: 1-51.

Kelsey L.P. 1957: The Skeleto-motor mechanism of the dobson fly, Corydalus cornutus. Part II. Pterothorax. Cornell Univ. Mem. 346: 1-42.

Korn W. 1943: Die Muskulatur des Kopfes und des Thorax von Myrmeleon europaeus und ihre Metamorphose. Zool. Jb. Anat. 68: 273-330.

KRAMER S. 1954: The musculature of the head of the phantom crane fly larva Bittacomorpha (Liriopeidae). J. Morphol. 94: 409-437.

KRAMER S. 1955: The musculature of the head of the Corydalus larva (Neuroptera, Sialidae). J. Morphol. 96: 1-30.

KRISTENSEN N.P. 1984: The larval head of Agathiphaga (Lepidoptera, Agathiphagidae) and the lepidopteran groundplan. Syst. Entomol. 9: 63-81.

KRISTENSEN N.P. 1999: Phylogeny of endopterygote insects, the most successful lineage of living organisms. Eur. J. Entomol. 96: $237-253$.

KRISTENSEN N.P. (ed.) 2003: Lepidoptera, Moths and Butterflies. Vol. 2: Morphology, Physiology, and Development. Handbook of Zoology. Vol. IV. Arthropoda: Insecta. Part 36. Walter de Gruyter, Berlin, New York, 564 pp. 
KubRakiewicz J. 1998: Neuropteroidea - different ovary structure in related groups. Fol. Histochem. Cytobiol. 36: 179-187.

Lawson F.A. 1991: Chrysomelidae (Chrysomeloidea) (= Cassididae, Cryptocephalidae, Megalopodidae, Sagridae, etc.). In Stehr F.W. (ed.): Immature Insects. Vol. II. Kendall/Hunt Publishing Company, Dubuque, Iowa, pp. 568-585.

MACLeod E.G. 1964: A Comparative Morphological Study of the Head Capsule and Cervix of Larval Neuroptera (Insecta). $\mathrm{PhD}$ dissertation. Harvard University, Cambridge, Massachussetts, iii $+528 \mathrm{pp}$.

MAKI T. 1936: Studies on the skeletal structure musculature and nervous system of the Alder Fly Chauliodes formosanus Petersen. Mem. Fac. Sci. Agric. Taihoku Imp. Univ. 16: 117-243.

Malicky H. 1973: Trichoptera (Köcherfliegen). Handbuch der Zoologie IV, Insecta. Inst. 29. Walter de Gruyter, Berlin, 114 pp.

MatsudA R. 1965: Morphology and evolution of the insect head. Mem. Am. Entmol. Inst. 4: 1-334.

Melzer R.R., Paulus H.F. \& Kristensen N.P. 1994: The larval eye of nannochoristid scorpionflies (Insecta, Mecoptera). Acta Zool. 75: 201-208.

Neunzig H.H. \& BAKeR J.R. 1991: Order Megaloptera. In Stehr F.W. (ed.): Immature Insects. Vol. II. Kendall/Hunt Publishing Company, Dubuque, Iowa, pp. 112-122.

New T.R. 1991: Neuroptera. In CSIRO (ed.): The Insects of Australia. Vol. 1. Melbourne University Press, Carlton, pp. 525-542.

New T.R. \& Theischinger G. 1993: Megaloptera, Alderflies and Dobsonflies. Handbuch der Zoologie. Vol. 4 (Arthropoda: Insecta), Part 33. Walter de Gruyter, Berlin, 97 pp.

PARKER H.L. 1935: Note on the anatomy of tenthredinid larvae with special reference to the head. Boll. Lab. Zool. Gen. Agr. Reale Scuola Sup. Agr. 28: 159-191.

Paulus H.F. 1986: Comparative morphology of the larval eyes of Neuropterida. In Gepp J., Aspöck H. \& Hölzl H. (eds): Recent Research in Neuropterology. Proceedings of the $2^{\text {nd }}$ International Symposium on Neuropterology, Hamburg, pp. $157-164$.

PILGRIM R.L.C. 1972: The aquatic larva and the pupa of Choristella philpotti Tillyard, 1917 (Mecoptera: Nannochoristidae). Pacif. Insects 14: 151-168.

PoHL H. 2000: Die Primärlarven der Fächerflügler - evolutive Trends (Insecta, Strepsiptera). Kaupia 10: 1-144.

RÖBER H. 1942: Morphologie des Kopfes und des Vorderdarmes der Larve und Imago von Sialis flavilatera. Zool. Jb. Anat. 67: 61-118.

Rousset A. 1966: Morphologie céphalique des larves de Planipennes (Insectes: Neuroptéroides). Mem. Mus. Natn. Hist. Nat. Paris (A) 42: 1-199.
Russel L.K. 1982: The life history of Caurinus dectes Russell, with a description of the immature stages (Mecoptera: Boreidae). Entomol. Scand. 13: 225-235.

SHARIF M. 1937: On the internal anatomy of the larva of the ratflea Nosopsyllus fasciatus (Bosc). Phil. Trans. R. Soc. London (B) 227: 465-538.

Smith D.R. \& MiddlekaufF W.W. 1987: Suborder Symphyta. In Stehr F.W. (ed.): Immature Insects. Vol. I. Kendall/Hunt Publishing Company, Dubuque, Iowa, pp. 618-648.

Stehr F.W. 1987: Order Lepidoptera. Description. In Stehr F.W. (ed.): Immature Insects. Vol. I. Kendall/Hunt Publishing Company, Dubuque, Iowa, pp. 289-293.

ŠTYS P. \& BILIŃSKI S.M. 1990: Ovariole types and the phylogeny of hexapods. Biol. Rev. 65: 401-429.

TARTER D.C., WATKINS W.D. \& EtNIER D.A. 1979: Larval description and habitat notes of the fishfly Neohermes concolor (Davis) (Megaloptera: Corydalidae). Entomol. News 90: 29-32.

Tarter D.C., Watkins W.D. \& Little M.L. 1975: Larval description and habitat notes of the fishfly Nigronia fasciatus (Megaloptera: Corydalidae). Psyche 82: 81-88.

TAuBER C.A. 1991: Order Raphidioptera. Order Neuroptera. In Stehr F.W. (ed.): Immature Insects. Vol. II. Kendall/Hunt Publishing Company, Dubuque, Iowa, pp. 123-143.

Theischinger G. 1991: 32. Megaloptera (Alderflies, dobsonflies). In CSIRO (ed.): The Insects of Australia. Vol. 1. Melbourne University Press, Carlton, pp. 516-520.

Whiting M.F. 2002: Phylogeny of the holometabolous insect orders: molecular evidence. Zool. Scr. 31: 3-15.

WidHALM-FinKE S. 1974: Funktionsanatomie des Larvenkopfes von Ctenocephalides felis felis B. Zool. Jb. Anat. 92: 497-518.

Wiggins G.B. 1987: Order Trichoptera. In Stehr F.W. (ed.): Immature Insects. Vol. I. Kendall/Hunt Publishing Company, Dubuque, Iowa, pp. 253-287.

WINKLER D. 1959: Die Muskulatur der Larve von Limnophilus flavicornis Fabr. Dt. Entomol. Z. (N.F.) 6: 112-128.

Winterton S.L. 2003: Molecular phylogeny of Neuropterida with emphasis on the lacewings (Neuroptera). Entomol. Abh. 61: $158-160$.

WundT H. 1961: Der Kopf der Larve von Osmylus chrysops L. (Neuroptera, Planipennia). Zool. Jb. Anat. 79: 557-662.

ZwICK P. 1967: Beschreibung der aquatischen Larve von Neurorthus fallax (Rambur) und Errichtung der neuen Planipennierfamilie Neurorthidae fam. nov. Gewäss. Abwäss. 44/45: $65-86$.

Received February 8, 2008 revised and accepted July 31, 2008 